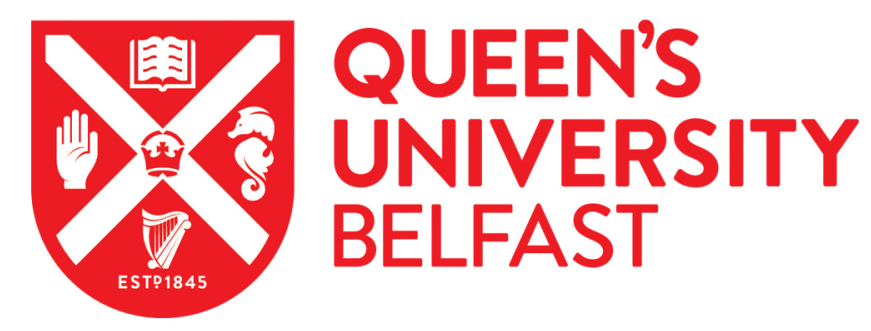

\title{
The development and validation of a quality by design based process analytical tool for the inline quantification of Ramipril during hot-melt extrusion
}

Dadou, S. M., Senta Loys, Z., Almajaan, A., Li, S., Jones, D. S., Healy, A. M., Tian, Y., \& Andrews, G. P. (2020). The development and validation of a quality by design based process analytical tool for the inline quantification of Ramipril during hot-melt extrusion. International Journal of Pharmaceutics, 584.

https://doi.org/10.1016/j.ijpharm.2020.119382

Published in:

International Journal of Pharmaceutics

Document Version:

Peer reviewed version

Queen's University Belfast - Research Portal:

Link to publication record in Queen's University Belfast Research Portal

\section{Publisher rights}

Copyright 2020 Elsevier.

This manuscript is distributed under a Creative Commons Attribution-NonCommercial-NoDerivs License

(https://creativecommons.org/licenses/by-nc-nd/4.0/), which permits distribution and reproduction for non-commercial purposes, provided the author and source are cited.

\section{General rights}

Copyright for the publications made accessible via the Queen's University Belfast Research Portal is retained by the author(s) and / or other copyright owners and it is a condition of accessing these publications that users recognise and abide by the legal requirements associated with these rights.

\section{Take down policy}

The Research Portal is Queen's institutional repository that provides access to Queen's research output. Every effort has been made to ensure that content in the Research Portal does not infringe any person's rights, or applicable UK laws. If you discover content in the

Research Portal that you believe breaches copyright or violates any law, please contact openaccess@qub.ac.uk. 
1 The development and validation of a quality by design based process 2 analytical tool for the inline quantification of Ramipril during hot-melt extrusion

4 Suha M. Dadou ${ }^{1}$, Zoe Senta-Loys ${ }^{1}$, Ammar Almajaan ${ }^{1}$, Shu Li ${ }^{1}$, David S. Jones ${ }^{1}$, 5 Anne M. Healy ${ }^{2}$, Yiwei Tian ${ }^{1}$, Gavin P. Andrews ${ }^{1 *}$

$6 \quad{ }^{1}$ Pharmaceutical Engineering Group, School of Pharmacy, Queen's University 7 Belfast, Belfast, United Kingdom

$8 \quad{ }^{2}$ School of Pharmacy and Pharmaceutical Sciences, Trinity College Dublin, Dublin, 9 Ireland

10 * Corresponding author: School of Pharmacy, 97 Lisburn Road, Belfast BT9 7BL, 11 United Kingdom.

12 Tel: +4428 90972646

13 Email: g.andrews@qub.ac.uk (G.P. Andrews) 
Continuous processing is superseding conventional batch processing as a means of manufacturing within the pharmaceutical research/industry. This paradigm shift has led to the implementation of Process Analytical Technology (PAT) as a semiautomatic, predictive tool offering real-time quality control that can be built into the production line. However, PAT tools have been mainly utilised to monitor a single process (e.g. powder blending, synthesis of biopharmaceuticals and small molecules) rather than a full continuous manufacturing process. In addition, there is a paucity of guidance documents that consider the continuous and dynamic conditions of realtime measurements for validation purposes. In this study, the feasibility of developing and validating a predictive and reliable Raman method based on quality by design $(\mathrm{QbD})$ and PAT frameworks for the real-time quantification of Ramipril (RMP) during hot-melt extrusion (HME) were investigated. Through QbD, a design space elucidating the quality attributes of RMP stability was successfully identified based on offline HPLC measurements. Process temperature and powder feeding rate were the main quality attributes to affect the stability of RMP during HME. The optimum combination of process and formulation variables were extracted from the validated design space and used to extrude RMP at a concentration range of $2.5-12.5 \% \mathrm{w} / \mathrm{w}$. Three calibration models were established using PLS regression analysis. The developed PLS calibration models showed excellent linearity $(R 2=0.989,0.995,0.992)$, accuracy $(\mathrm{RMSECV}=0.31,0.26,0.30 \%)$ and specificity $(\mathrm{PC} 1=81,85,89 \%)$ for models 1 , 2 and 3, respectively. Furthermore, the developed QbD-PAT model was able to predict the quantity of RMP at varied process feed rate $(10,35 \mathrm{rpm})$ operating under long processing time $(60 \mathrm{~min})$. The output of this study allows in-process optimisation of formulation and process variables to control the quality and quantity of RMP during HME. Furthermore, it allows the implementation of PAT tools as routine methods of analysis within the laboratory. 


\section{Introduction}

43 Over the last 20 years, the pharmaceutical industry has observed a paradigm shift in

44 how drug products are manufactured and quality assured. Recent advances and innovation in manufacturing technology has resulted in a drive towards continuous production of pharmaceuticals and biopharmaceuticals (Lee, 2017; Lee et al., 2015; Poechlauer et al., 2012). Continuous manufacturing allows pharmaceutical drug products to be produced in a single-step, eliminating major concerns associated with traditional multi-step, batch processing, which often requires additional guidelines to maintain quality (Badman and Trout, 2015; Kelleher et al., 2018; WHO, 2015). In addition, continuous manufacturing is an environmentally friendly process that offers a more efficient and safe production method of pharmaceuticals with reduced associated human error (Kleinebudde et al., 2017; Lang et al., 2014). Moreover, given the significant and rapid recent advances in machine learning, the transition from the conventional batch production to continuous manufacturing in the near future is inevitable.

Continuous processing has already been implemented as a mean of manufacturing in chemical and petrochemical industries. Despite this, the transition to such an innovative manufacturing platform in the pharmaceutical industry is still in its early stages. This stems from the need to reconsider the infrastructure in the pharmaceutical industry which includes purchasing new equipment and retraining personnel (Lee, 
obstacles to effective use of this technology and ultimately product approval (Woodcock and Woosley, 2008). Despite these challenges, the FDA is helping to facilitate the switch to continuous manufacturing by providing financial incentives to support research, training resources for personnel and guidance documents. For example, the Emerging Technology Program was established by the Centre for Drug Evaluation and Research (CDER) to support modernisation of the pharmaceutical industry and the transition to innovative manufacturing technologies. The sector has responded well to such initiatives and there some have implemented innovative technologies and received FDA approval for drug products prepared using continuous manufacturing (FDA, 2019).

To accommodate the needs of this emerging view of pharmaceutical manufacturing, there was a requirement for parallel innovation in process development and quality control/assurance of drug products. In response, the ICH and FDA released Quality by Design (QbD) and Process Analytical Technology (PAT) regulatory frameworks to facilitate the implementation of innovative manufacturing platforms in the pharmaceutical industry (FDA, 2004; ICH, 2009). QbD allows quality to be built into the process/formulation design (ICH, 2009). Integrating PAT to QbD enables the realtime monitoring and analysis of materials and processes during manufacturing, which offers an in-depth understanding of the critical attributes affecting the quality of the end products (Laske et al., 2017; Moore, 2012). The digital innovation and integration of $\mathrm{QbD}$ and $\mathrm{PAT}$ in continuous manufacturing has led to a data rich sector for quality 
assessment and control. Thus, formulations/processes can be designed and controlled, accordingly, to meet the quality intended. Conversely, conventional batch methods only allow for process performance evaluation through assessment of the quality of the end product (Fonteyne et al., 2015; Gouveia et al., 2017). In essence, the concept of $\mathrm{QbD}$ and PAT being that quality cannot be tested into end products, rather it should be built-in to product during the process (Ohno, 1988).

PAT tools collect real-time data of materials during processing by employing noninvasive sensing technologies (Wirges et al., 2013). These technologies, (e.g., vibrational spectroscopy and ultrasound), are commonly used in pharmaceutical manufacturing as tools to monitor the quality of drug product (Netchacovitch et al., 2015). This is due to the non-invasive and rapid nature of these technologies (Müller et al., 2012). Additionally, spectra can be obtained using small amounts of the materials from a wide range of pharmaceutical forms with no sample preparation (Dadou et al., 2020). Recent and significant advances in chemometrics, has enabled the efficient analysis of spectral data. Hence, vibrational spectroscopy has been widely employed in real-time monitoring and quality control of different pharmaceutical processes such as drug synthesis, crystallization, powder blending, granulation, coating, tablet manufacturing and hot melt extrusion (Kelly et al., 2012; Li et al., 2018; Pauli et al., 2019; Sahnić et al., 2016).

In our previous work, the feasibility of utilizing hot melt extrusion (HME) as a continuous processing platform for the thermolabile drug Ramipril (RMP) was 
demonstrated (Andrews et al., 2019). Offline HPLC and LC-MS were used as reference methods to quantify RMP and its degradation product ramipril-diketopiperazine 107 (RMP-DKP). Furthermore, a detailed investigation on the selection of the Raman wavenumber region to be used for the analysis of RMP and RMP-DKP using principal component analysis (PCA) scatterplots were investigated. Results revealed that the wavenumber region from 950 to $1250 \mathrm{~cm}^{-1}$ showed the best fit for Raman data. The aim

111 of this study was to advance our understanding further and to develop and validate 112 an inline Raman-based PAT tool based on an optimised design space to monitor, 113 control and, thereafter, predict the quality of RMP during HME. A QbD approach was 114 adopted in building the experimental design model, to identify the source of variability for RMP integrity during the HME process and optimise the design space for the development of the PAT method. Additionally, further information needed for

117 the development of the PAT method were extracted from inline Raman spectra using 118 chemometrics. Internal and external validation were carried out to test the suitability 119 of the developed method for the inline quantification of RMP. 
121

122

123

124

125

126

127

128

129

130

131

132

133

134

135

136

137

138

139

140

\section{Materials and Methods}

\subsection{Materials}

Ramipril (RMP) was purchased from Kemprotec (Carnforth, England). Eudragit EPO (EPO) and Eudragit L 100 (L100) were obtained from Evonik Industries (Darmstadt, Germany). Triethyl citrate (TEC) was purchased from Lancaster synthesis Ltd (Morecambe, UK).

\subsection{Design of Experiments (DoE)}

DoE was employed in this work to optimise the process and formulation by investigating the impact of formulation and process parameters on the integrity of RMP during hot melt extrusion (HME). Four quantitative variables, including process temperature (T), powder feeding rate (FR), screw speed (SS) and plasticiser content (TEC), were investigated (Table 1). RMP concentration was fixed at $10 \%(\mathrm{w} / \mathrm{w})$ while the polymer to plasticiser ratio was changed depending on the content of TEC $(\% \mathrm{w} / \mathrm{w})$ used. The ratio of EPO:L100 was kept constant at 1:1 in all formulations. The concentration of RMP and RMP-DKP (\% w/w) in the extrudates were assigned as responses in this study and were measured offline using HPLC.

MODDE Pro (version 12.1, Umetrics, Umeå, Sweden) was used to establish the DoE model. A 2-level, full factorial design with centre-point control runs was employed. A total of twenty experiments, containing three repeated runs, having different combinations of variables were designed as shown in Table 2. 
142 HME was performed using a co-rotating, fully intermeshing twin-screw extruder

143 (Microlab, Rondol Technology Ltd, France). Physical mixtures of the drug, polymers

144 and plasticiser were mixed using a mortar and pestle. The premixed powder was fed 145 into the extruder using a twin-screw powder feeder (Rondol Technology Ltd, France).

146 Extrusion was performed at various conditions as outlined in Table 2. An in-house

147 designed, $2 \mathrm{~mm}$ diameter die was fitted to the end of the barrel to accommodate the 148 inline Raman probe (Andrews et al., 2019). The extrudates produced were collected 149 and stored in bags for further analysis.

\subsection{Inline Raman Spectroscopy Measurements}

151 A high temperature and pressure immersion HME Kaiser Probe (RAMAN RXN"M

152 Probe) was installed into the die. Raman Spectra were collected inline using a Raman

153 Rxn1 spectrometer (Kaiser Optical Systems, Ann Arbor, MI, USA) with an Invictus

154 NIR diode laser at a laser wavelength of $785 \mathrm{~nm}$ (Kaiser Optical Systems). All Raman

155 spectra were recorded using a laser power of $400 \mathrm{~mW}$ with a resolution of $2 \mathrm{~cm}^{-1}$ and

156 total exposure time of 10 seconds. Spectra were collected every 20 seconds during

157 extrusion. Data collection was automated using iC Raman software (version 4.1,

158 Mettler Toledo, US). Collected spectra were then transferred to SIMCA software

159 (version 15, Umetrics, Umeå, Sweden) for spectral pre-processing and chemometrics. 
HPLC offline analysis was undertaken to quantify RMP and RMP-DKP in the extrudates. The peak areas of RMP and RMP-DKP were used to calculate their concentration. A calibration curve was constructed for RMP with a concentration range from 5 to $50 \mu \mathrm{g} / \mathrm{mL}$. Linearity was observed with a goodness fit $\left(\mathrm{R}^{2}\right)$ of 0.997 . For the quantification of RMP-DKP, a sample of RMP was heated on a hot plate for 2 hours at $140^{\circ} \mathrm{C}$ to induce degradation. Obtained RMP-DKP was then dissolved in a mixture of acetonitrile and $\mathrm{HCl}(50: 50)$ and concentrations from 0.5 to $50 \mu \mathrm{g} / \mathrm{ml}$ were used to construct the calibration curve. Linearity was observed with a goodness of fit $\left(\mathrm{R}^{2}\right)$ of 0.9999. RMP-DKP concentration was then normalised to the concentration of RMP using Equation 1 (Andrews et al., 2019):

$$
\text { Normalised DKP }(\%)=\frac{\text { Peak area } D K P}{\text { Peak area } R M P} \times R M P_{\text {theoretical }}(\%)
$$

Following extrusion, pelletised extrudates were dissolved in $0.1 \mathrm{M} \mathrm{HCl}$ to obtain a final RMP concentration of $25-30 \mu \mathrm{g} / \mathrm{mL}$. Aliquots were withdrawn from the prepared samples, filtered through hydrophilic PTFE syringe filters $(0.45 \mu \mathrm{m}$, Fisher Scientific Ireland Ltd., Dublin, Ireland) then analysed using an Agilent 1260 Infinity Series HPLC (Agilent Technologies, Cheadle, UK). A Kinetex® C18 column (150 mm × 4.6 $\mathrm{mm}$, phenomenex, Torrance, USA) was used as the stationary phase. $10 \mu \mathrm{L}$ of each sample was injected to the column using an auto-sampler. The mobile phase consisting of an aqueous solution of $0.1 \mathrm{M}$ sodium perchlorate adjusted to $\mathrm{pH} 2.5 \mathrm{using}$ phosphoric acid (mobile phase A), and acetonitrile (mobile phase B) was pumped to 
181 the system under gradient mode at varied flow rates between 0.8 and $1.5 \mathrm{~mL} / \mathrm{min}$ 182 (Andrews et al., 2019). Detection was achieved using a UV detector at a wavelength 183 of $210 \mathrm{~nm}$.

\section{2.6. Principal component analysis (PCA)}

185 The analysis of the Raman spectra collected during extrusion was achieved using SIMCA software (version 14.1, Umetrics, Umeå, Sweden). To reduce random noise and baseline drift in the signal, particularly at high temperature, Standard Normalised Variate (SNV), Multiplicative Scatter Correction (MSC) and 15-point quadratic Savitzky-Golay (SG) pre-processing spectral filters were considered. Analysis was performed on the spectral region of $950-1250 \mathrm{~cm}^{-1}$ which allowed for the characterization of pure RMP and its degraded product (RMP-DKP) (Andrews et al., 2019). Principal Component Analysis (PCA) was performed to identify the principle components of the spectra collected during HME.

Partial Least Square (PLS) calibration models for RMP (\%) was established by correlating the Raman spectra obtained during HME processing with the concentration measured using offline HPLC. Parameters used to evaluate the PLS model performance were the coefficient of determination of predictions $\left(\mathrm{R}^{2} \mathrm{X}\right)$, coefficient of determination of observations $\left(R^{2} Y\right)$, model validity $\left(Q^{2}\right)$, root mean 
squared error of estimation (RMSEE) and root mean squared error of cross validation (RMSEcv).

202

The optimum combination of formulation and process conditions, obtained from the

DoE design space, was used to develop and validate the PAT method. A calibration set composed of formulations containing 2.5, 5, 7.5, 10 and $12.5 \% \mathrm{w} / \mathrm{w}$ of RMP was prepared and extruded. Inline Raman spectra were collected and predicted levels of RMP in the extrudates were plotted against the values measured using the reference method (HPLC).

For the validation, a validation set (which includes runs that were not used in the calibration set) composed of formulations containing 4, 6, 7 and 9 (\% w/w) RMP was formulated and extruded. Validation parameters including selectivity, range,

211 linearity, accuracy, precision and robustness were assessed to meet the criteria established in the International Council for Harmonization on the validation of analytical procedure (ICH-Q2), the European Medicines Agency (EMA) guideline on

214 the use of near infrared spectroscopy and the US-FDA draft guidance on the 215 Development and Submission of Near Infrared Analytical Procedures as follows 216 (EMA, 2009; FDA, 2015; ICH, 2005):

217 Linearity. Three calibration models were established, on three consecutive days, using Raman spectra collected for the calibration set. The linearity was evaluated using PLS regression to correlate the values of RMP (\%) predicted from Raman with the values 
measured from the HPLC reference method. The coefficient of determination $\left(\mathrm{R}^{2}\right)$,

Selectivity. To evaluate the selectivity/specificity of the method, inline Raman spectra obtained from a formulation containing RMP was compared with (i) the spectra collected from a formulation containing the carrier only (polymers mixture and TEC) to assess the capability of the method to distinguish and quantify RMP unequivocally in presence of other ingredients, and (ii) the loading plot obtained for the principal component of the PLS calibration model to assess its capability to describe the main features of the collected inline Raman spectra. to the true values measured using the reference method. Three parameters were considered to assess accuracy. Root mean square error of estimation (RMSEE) and cross validation (RMSEcv) were estimated from the calibration set while root mean square error of prediction (RMSEP) was obtained from the validation set. The RMSEE/cv and RMSEP can be calculated using Equations 2 and 3 (Li et al., 2018):

$$
\begin{aligned}
& \operatorname{RMSE}(E / c v)=\sqrt{\frac{\sum\left(\hat{\mathrm{y}}_{i}-y_{i}\right)^{2}}{n-N}} \\
& R M S E P=\sqrt{\frac{\sum\left(\hat{\mathrm{y}}_{i}-y_{i}\right)^{2}}{n}}
\end{aligned}
$$
concentrations by HPLC, $\mathrm{n}$ represents the number of samples in the data set, and $\mathrm{N}$ is the number of variables considered in the model. 
Precision. Precision measures the closeness of multiple measurements of the same sample under same condition. Relative standard deviation (RSD, \%) and RMSEP of the validation set are used as validation parameters to evaluate precision. The definition of precision in existing guidelines and the recommended methods for assessment are more suitable for offline measurements and not applicable for inline measurements. In this work, repeatability (intraday precision) was evaluated by acquiring Raman spectra at predetermined time intervals of the extrusion process and collecting samples from the produced extrudates that match the time at which the spectra were obtained. Intermediate/Interday precision (within-lab) and reproducibility (between-lab precision) are not achievable in agreement with the ICH, EMA and US-FDA guidelines since the same sample cannot be analysed inline more than once. Therefore, in this work the experiments, for the validation set, were repeated at three consecutive days, RSD and RMSEP were calculated, and the values obtained were reported as parameters for the interday precision considering that the same formulations, methods, conditions and Raman probe were used.

Robustness. Robustness is a measure of the capability of the method to remain unaffected by small variations in process/formulation variables. Raman spectra

257 employed in the DoE investigation were used to address the robustness of the method 258 since the spectra were collected at different formulation and process conditions. 259 Parameters including $\mathrm{R}^{2}$, slope, intercept, RMSEE, RMSEcv and RMSEP were used to assess the robustness of the PAT method. 
262 The capability of the developed Raman-PLS model to capture the changes in the 263 quality of RMP when altering the process conditions was evaluated. The PLS 264 calibration model obtained from the inline Raman spectra collected during the DoE 265 experiments was used. The experiment was performed using a sample with 10\% RMP, $266 \mathrm{w} / \mathrm{w}$. The potential impact of feed rate on the quality of RMP during HME processing 267 was demonstrated by varying the FR between its upper and lower limits of the 268 optimised/validated design space (10 and $35 \mathrm{rpm}$ ) over $60 \mathrm{~min}$ extrusion time. The 269 extrudates were then analysed using offline HPLC. RMP content obtained from HPLC 270 and the developed Raman-PLS model were then directly compared. In addition, the 271 RMP values predicted using the optimised design space were reported. 


\section{Results and Discussion}

\subsection{Screening of Variables Affecting RMP Integrity using DoE}

275

Having a good understanding of the formulation and the manufacturing process is a critical part of drug development (Moore, 2012). A DoE approach was adopted in this work to deliver a further understanding of the formulation and process parameters that affect the stability of RMP during HME. A total of 20 experiments were performed (Table 2). It is worth noting that experiments N3 and N7 were not extrudable due to the high back pressure at the die exit which exceeded the upper limit of the extruder, 100 bar.

Given the fact that all the trial runs were conducted at a fixed initial RMP loading ( $10 \%$ $\mathrm{w} / \mathrm{w})$, results shown in Figure 1 clearly indicate that temperature $(\mathrm{T})$ is the main variable affecting the RMP and RMP-DKP $(\% \mathrm{w} / \mathrm{w})$ content in the extrudates. An increased temperature results in a negative contribution on RMP stability and a subsequent positive contribution to RMP-DKP content. No direct effect on RMP integrity was associated with SS and TEC within the studied ranges, therefore, their roles were not highlighted in this work. Feed rate (FR), on the other hand, showed a positive impact on RMP stability and a negative impact on RMP-DKP content. This can be explained by the fact that increasing the FR will reduce the residence time of materials within the extrusion barrel and, therefore, the formulation will be exposed to the high $\mathrm{T}$ in the barrel for shorter time periods (Reitz et al., 2013). In contrast, the square factor of feed rate (FR*FR) showed a negative impact on RMP content. This can 
294 be explained by the specific mechanical energy in the extruder barrel. Specific mechanical energy is defined as the amount of energy input during extrusion (Repka et al., 2013). It is affected by the shear stress, pressure and torque in the extruder and, hence, can be optimized by varying the FR and SS. And since SS showed no significant effect on RMP stability within the studied range, we postulate that at a certain level of FR, the pressure and torque, and hence the specific mechanical energy, reach values sufficiently high to promote RMP degradation during HME processing. This observation is supported by the positive effect that FR*FR exerted on RMP-DKP content (Figure 1b), suggesting a non-linear relationship between FR and RMP concentration in the extrudate. On the other hand, it is evident from the coefficient plot (Figure 1) that the interaction term between FR and $\mathrm{T}\left(\mathrm{FR}^{*} \mathrm{~T}\right)$ promotes $\mathrm{RMP}$ integrity. This observation implies that increasing the FR can compensate the degradation caused by high $\mathrm{T}$.

Figure 2 shows the design space predicting RMP concentration in the extrudates as a function of each set of variables. The contour lines represent the probability of failure of the variables to result in the optimum RMP concentration (9-11 \%) which was based on a 95\% confidence interval. Therefore, the green area represents the combination of variables that results in RMP concentration in the specified range with a probability

312 of failure of $\leq 5 \%$, whereas the red area represents the set of variables that will fail to meet the target concentration of RMP with a probability of failure $>5 \%$. 
315 The validity of the design space that was obtained from the DoE model in predicting RMP concentration within the hot melt extrudates was investigated. Six validation runs (Table 3) having different combinations of the independent variables were selected from the design space (Figure 2) and extruded. RMP and RMP-DKP (\% w/w) contents in the extrudates were measured using HPLC to verify the predicted values from the DoE. Three runs were selected from the green region (V3, 4 and 6), whereas the other three runs (V1, 2 and 5) were selected from the red region. Obtained results from the HPLC were close to the prediction established by the DoE model (Table 3). RMP-DKP content in extrudates was in general aligned to values obtained from HPLC.

\subsection{Chemometrics}

To shed more light on the correlation between studied variables and responses and try to find patterns and/or categories that can better describe the interaction between the variables, chemometrics was employed (Gabrielsson et al., 2002). In a previous study, we conducted a thorough investigation of the Raman shift region that best represents RMP and RMP-DKP in the inline Raman spectra, collected from the die, using principal component analysis (PCA) (Andrews et al., 2019). Based on the findings, a Raman spectral region of 950 - $1250 \mathrm{~cm}^{-1}$ was adopted in this work (Figure 3a). Partial least square (PLS) regression was used to fit the collected spectra. A comparison between the most common filters was conducted to examine the pre- 

for the PLS model established from the spectra that were pre-processed using SNV, MSC and SG spectral filters. Thus, Raman spectra were pre-processed using the three filters throughout this study.

The PC1 versus PC2 scatterplots are presented in Figure 3 (b, c). PCA scatterplots have been obtained with PC1 explaining $88 \%$ of results. Sample clusters were orientated along PC1 with weakly degraded samples observed on the negative side and highly degraded samples on the positive side of x-axis. The concentration of RMP and RMPDKP were clearly linked since RMP is transformed into RMP-DKP by cyclization and/or condensation (Shafiq and Shakeel, 2008). Thus, when RMP content was high (8-10\%), a low percentage of RMP-DKP (0.2-3\%) was recovered. In contrast, when

347 RMP content was low (2- 7\%), high concentrations of RMP-DKP (4- 8\%) were observed.

Figure 4a shows PCA scatterplot grouped based on T and FR values due to the significant effect they have on the integrity of RMP. It can be observed that samples extruded at $140^{\circ} \mathrm{C}$ are on the positive side corresponding to samples with high RMPDKP content. Conversely, samples extruded at 100 and $120^{\circ} \mathrm{C}$ were observed on the negative side associated with RMP drug content $\geq 8 \%$. This implies, again, the direct relationship between $\mathrm{T}$ and RMP degradation and the subsequent production of RMP- 
higher RMP content when mixtures were fed at a rate of $40 \mathrm{rpm}$ (blue) compared to

$35710 \mathrm{rpm}$ (pink). This is in agreement with the results obtained from the DoE study.

358 PCA was used to describe samples depending on their colour and TEC content (\% $359 \mathrm{w} / \mathrm{w})$. Figure $4 \mathrm{~b}$ shows that samples were well orientated along PC 2. Extrudates 360 obtained without TEC were observed on the negative side, while extrudates with $5 \%$ and $10 \%$ of TEC were observed on the origin and the positive side of the $y$-axis, respectively. Additionally, different clusters were identified based on the colour of the extrudates. According to Figure $4 \mathrm{~b}$, the most degraded samples were brown regardless of TEC concentration. Slightly yellow and transparent extrudates were localized on the positive side of PC 2, corresponding to formulations prepared at TEC concentrations of $5 \%$ and $10 \% \mathrm{w} / \mathrm{w}$, respectively. Samples localised on the negative side of PC 2, at $0 \%$ TEC, were white and opaque. This indicates, again, that TEC content does not affect the integrity of RMP when incorporated in the formulation at ratios up to $10 \% \mathrm{w} / \mathrm{w}$.

\subsection{The Development and Validation of the Raman based PAT Method}

371 Following the DoE and chemometrics studies, optimisation of the process and 372 formulation variables that result in the desired concentration of RMP within the extrudates was carried out. The plot in Figure 5a displays the predicted RMP (\% w/w) at each variable set combination. The green and blue regions represent the values of variables that result in the target concentration of RMP (9-11\%). The dynamic plot 
On the other hand, an inverse linear correlation was observed between RMP and T.

FR exhibited a complex relationship with RMP. The integrity of RMP was enhanced with FR up to a certain limit where a curvature in the plot is observed. This, again, can be explained by the specific mechanical energy inside the extruder barrel previously discussed and supports our claim of the presence of a non-linear relationship between FR and RMP content. The optimum set point suggested was adopted for the development and validation of the Raman based PLS calibration model as follows: $\mathrm{T}=$ $106{ }^{\circ} \mathrm{C}, \mathrm{FR}=32 \mathrm{rpm}, \mathrm{SS}=80 \mathrm{rpm}$ and $\mathrm{TEC}=7.3 \% \mathrm{w} / \mathrm{w}$.

The objective of validation is to ensure that each measurement performed using the method developed was similar to the true value of the unknown sample (ICH, 2005). Existing guidelines do not accommodate the needs of such innovative platforms. The European Medicines Agency (EMA) and United States Food and Drug Administration (US-FDA) have published practical guidance on the development and validation of near infrared (NIR) analytical procedures (EMA, 2009; FDA, 2015). The guidelines outline the tests and statistics required to ensure the applicability and reliability of the developed offline spectroscopy based chemometrics method. The stress conditions and dynamic nature of samples during continuous processing were not considered in the guidance. EMA guidelines state: “Because PAT NIRS procedures are specific to the nature of the manufacturing process, it is not appropriate to prescribe exact requirements for such procedures in this guideline". On the other hand, US-FDA 
guidelines propose the applicability of the guidance for inline methods. Nevertheless, intermediate precision which involves measuring the same sample on different days or by different analysts "should also be determined" (FDA, 2015). Such requirement is not attainable for inline methods. It is worth noting that both guidelines were proposed for NIR spectroscopy, however, they are applicable to Raman spectroscopy as well.

Therefore, whilst several investigations have developed inline method for drug quantification purposes, very few have considered the feasibility of validating the established methods (De Leersnyder et al., 2018; Hubert et al., 2007; Saerens et al., 2014b; Zhang et al., 2019). A NIR based PAT method was developed and validated for the production of a drug product (Zhang et al., 2019). All validation parameters were calculated with the exception of precision which was considered unachievable. When developing a PAT method for blend monitoring, the intraday precision (repeatability) parameters can be obtained by shutting the feeding and the turret off (De Leersnyder et al., 2018). Thus, spectra can be collected from the same rotating powder. This is not achievable when employing hot melt extrusion (HME). In another study, a validation strategy which was based on the total error of the method, was adopted (Hubert et al., 415 2007) wherein acceptable drug levels and tolerance levels were identified and each 416 measurement represented the true value and the bias (De Leersnyder et al., 2018; 417 Saerens et al., 2014b). Again, not all validation parameters were obtainable. 
Therefore, in this work, several guidance documents that are implemented for offline analysis were considered. These include, the ICH Harmonised Guideline on the

Validation of Analytical Procedure, the EMA Guideline on the use of near infrared spectroscopy and the US FDA draft guidance on the Development and Submission of Near Infrared Analytical Procedures (EMA, 2009; FDA, 2015; ICH, 2005). For the development of chemometrics based models, the following criteria should be fulfilled (EMA, 2009; FDA, 2015):

(i) The selection of the wavenumber range of the Raman spectra does not need to include the full range. However, considering a narrow region around the characteristic Raman shift can restrict the model performance (FDA, 2015). Therefore, a thorough study on the model performance using different regions should be delivered. In our previous work, a detailed investigation was delivered in order to find and justify the optimum spectral region to avoid under and/or overfitting of the data (Andrews et al., 2019). Using PCA analysis, the wavenumber region of 950 to $1250 \mathrm{~cm}^{-1}$ showed high capability in identifying the variables that affect RMP integrity during HME qualitatively and in distinguishing between RMP and its degradation product (RMP-DKP). In addition, the PLS calibration model developed was able to predict RMP concentration with good linearity and accuracy $\left(\mathrm{R}^{2}\right.$ 0.94, RMSEC 1.05, RMSEcv 1.12). Therefore, the same region was adopted in this work. Table 4 shows 437 the suitability of the selected spectral pre-processing filter for the inline quantification of RMP during HME. 
439

440

441

442

443

444

445

446

447

448

449

450

451

452

453

454

455

456

457

458

459

460

(iii) Potential outliers in the calibration model should be investigated. A potential outlier is a sample that shows an atypical spectrum and/or has high residuals (EMA, 2009). Such sample should be considered an outlier and be excluded from the PLS model. It is recommended to use built-in diagnostic tools within the software to analyse outliers (FDA, 2004). Hotelling's T-squared Distribution (Hotelling's T2) test and distance to the model (DModX) analysis were used. The Hotelling's T2 test is an extension of the student's t-test and is adopted in multivariate analysis. Calculated values represent the distance for each sample from the origin/centre of the model (Nagy et al., 2017). Thus, a large T2 range for a given sample is an indication that it is far from other samples in the score space of the model. Hence, it is likely to be an outlying observation that may detrimentally distort the calibration model and, subsequently, give false results for unknown samples (Brouckaert et al., 2016). Values larger than the $95 \%$ confidence limit are suspect, while values larger than the $99 \%$ confidence limit can be considered as serious outliers and should be excluded from the calibration model. DModX is the distance of a sample/observation in the calibration model from the X plane (predicted values plane) (Saerens et al., 2014a). Potential outliers can be identified from the critical value (Dcrit) of the DModX which is computed by depending on the selected significance level $(\alpha=0.5)$ (Müller et al., 2012). Samples that show DModX values twice as large as Dcrit are considered as moderate outliers. To investigate if these samples are outliers, we investigated their residuals. Samples that showed extreme absolute residuals were considered as outliers. Three PLS calibration models were developed for the quantification of RMP 
(Figure 6). Twenty, two and seven outliers were identified and excluded from the developed model 1, 2 and 3, respectively. Hotelling's T2 and DModX plots for the three models after excluding the outliers are shown in Figure 7.

464 After addressing the guidance requirements for the development of a chemometrics 465 based method of analysis, validation was carried out. Two levels of validation were 466 considered, internal and external validation (EMA, 2009; FDA, 2015). Cross validation 467 method was considered for internal validation. This method comprises the removal 468 of one or more spectra from the calibration set and applying the calibration model on 469 the removed spectra to predict its value. Subsequently, the difference between the value predicted by the model and the true value of the removed sample was 471 calculated. The root mean square error of cross validation (RMSEcv) was used as the 472 validation parameter for this method. The smaller the number; the optimum the 473 model was for the analysis. Cross validation was carried out for the three developed 474 PLS calibration models. Calculated RMSEcv values are reported in Table 5. It is 475 observed that calculated values are very similar to the RMSEE values which indicates 476 the validity of the three models to accurately predict excluded samples. However, 477 results may indicate a possibility of overfitting (Zhang et al., 2019).

478 Following the development and internal validation of the inline Raman based PLS 479 calibration models, external validation was performed which included validating the 480 method for linearity, specificity, accuracy and precision. 
Linearity was estimated from the developed calibration curves. For PLS regression, the predicted RMP values from Raman spectra were plotted as the independent variables (x-axis); whereas, the measured values using the reference HPLC method were the dependent variables (y-axis). Coefficient of determination $\left(\mathrm{R}^{2}\right)$, slope and intercept were the metrics used to assess the linearity. For good linearity, it's expected that the $\mathrm{R}^{2}$ is close to unity with slope and intercept values that are not statistically different from 1 and 0, respectively. Results obtained (Figure 6 and Table 5) clearly show good linearity between the predicted and the measured RMP values with the ability of the PLS models to describe more than $98.9 \%$ of the variation in the results (model 2 and 3 can describe $\geq 99 \%$ of the variance). The slope value was 1 in the three models whereas the values of the intercept were very close to zero. Thus, linearity requirements were met in the developed model.

To confirm the specificity/selectivity of the method to quantify RMP in the presence of other ingredients, collected Raman spectra obtained for the formulations containing Ramipril were compared to the spectra obtained for a blank formulation (EPO, L100 and TEC). As shown in Figure 8a, the characteristic peak of Ramipril $\left(1004 \mathrm{~cm}^{-1}\right)$ was not observed in the spectra collected for the blank polymer mixture. No interference was observed between the Raman shift of RMP $\left(1004 \mathrm{~cm}^{-1}\right)$ and other ingredients present in the formulation when RMP was included in the formulation which proves the specificity of this method for RMP. Furthermore, the loading plot for the principal 501 component of the PLS calibration model (Figure 8b) was able to describe the main 
502 features of the original spectra that was used for the development of the PLS 503 calibration model, i.e. the characteristic peak of RMP. $\mathrm{R}^{2} \mathrm{X}$ values obtained from the 504 principal component of models 1, 2 and 3 were 81, 85 and 89\%, respectively. This, 505 again, confirms the specificity of the established PLS calibration models for the inline 506 quantification of RMP.

507 Accuracy was estimated from the RMSEE, RMSEcv and RMSEP values. RMSEE and 508 RMSEcv were calculated from the calibration set whereas the validation set was used 509 to calculate RMSEP. Large differences between the three parameters indicate a poor 510 calibration model that needed further optimisation/investigation. The values 511 calculated for RMSEE, RMSEcv and RMSEP from the three calibration models (Table 512 5) were lower than $1 \%$. This indicates the capacity of the developed model to predict 513 unknowns accurately.

514 Precision was evaluated from the calculated RSD and RMSEP values (Table 6). Despite 515 measurements being carried out in stress and dynamic conditions, the method 516 showed high precision in predicting the concentration of RMP in the validation set 517 with RMSEP values $<1 \%$ and RSD $<7 \%$ for both the intra and (the developed) interday 518 precision tests.

519 No further runs were considered to evaluate the robustness of the method since 20 520 runs were executed previously under different conditions of T, FR, SS and TEC 521 concentration to establish the DoE model (Table 2). The PLS calibration model 522 developed from the DoE model (Figure 9a) was used to assess Robustness. The model 
showed good linearity $\left(\mathrm{R}^{2}=0.955\right.$, slope $=1$, intercept $\left.\sim 0\right)$ and accuracy $(\mathrm{RMSEE}=0.63$,

524 RMSEEcv= 0.66). External validation was carried out using inline Raman spectra

525 collected from the validation runs employed in the DoE study (Table 3). The model

526 showed good prediction capability when compared with the true HPLC values

527 (RMSEP= 0.88). This indicates the capacity and robustness of the Raman based PAT

528 model to identify and quantify RMP under variable conditions.

\subsection{Inline Monitoring of RMP Content During HME Processing}

To demonstrate the capability of the established QbD-PAT model in predicting the quantity of RMP during HME processing, feed rate was altered between the upper and lower limits in accordance to the design space obtained from DoE (Figure 5). The RMP content within extrudates were predicted using the QbD design space and inline Raman-PAT tool during the 60-min trial run. The predicted RMP contents were then compared to the values obtained through the offline HPLC method. It was observed from the obtained RMP (\%) profile (Figure 10) that the predicted values for RMP using the developed Raman-PAT tool and the QbD optimised design space were within the $10 \%$ relative error window from true values (HPLC). This provides future evidence of the potential impact of process parameters on the integrity of RMP within extrudates

540 which was successfully captured using the inline QbD-PAT digital tool during the HME process. 


\section{Conclusion}

544 This work demonstrated through the adoption of a QbD-PAT framework, hot-melt

545 extrusion can be used as a continuous processing platform for the manufacture of

546 solid dosage forms containing thermolabile drugs. This was achieved through a

547 careful design of the HME process and in-process monitoring. A design space

548 indicating the probability of maintaining RMP integrity during the HME process was

549 first established based on a DoE, full-factorial model and offline HPLC measurements.

550 Following the identification and optimisation of the quality attributes that affect the

551 in-process stability of RMP and the validation of the obtained design space, an inline

552 Raman-based PLS model was developed and validated for the quantification of RMP

553 during HME. The established Raman-based PLS model enabled the correlation

554 between the design space for quality attributes and the quality of the response (RMP)

555 during the HME process. Thus, the quality of the dosage form can be designed and

556 built-in into HME and monitored inline throughout the process. It is envisaged that

557 the implementation of QbD-PAT will undoubtedly improve the quality and efficiency

558 of pharmaceutical manufacturing. 


\section{Acknowledgements}

This investigation was conducted with the financial support of both the Science Foundation of Ireland (SFI) under Grant Number 14/IA/2559 and the Department for the Economy of Northern Ireland.

\section{References}

Andrews, G., Jones, D., Senta-Loys, Z., Almajaan, A., Li, S., Chevallier, O., Elliot, C., Healy, A., Kelleher, J., Madi, A., 2019. The development of an inline Raman spectroscopic analysis method as a quality control tool for hot melt extruded ramipril fixed-dose combination products. International journal of pharmaceutics 566, 476-487.

Badman, C., Trout, B.L., 2015. Achieving Continuous Manufacturing May 20-21 2014 Continuous Manufacturing Symposium. Journal of pharmaceutical sciences 104, 779-780.

Brouckaert, D., Uyttersprot, J.-S., Broeckx, W., De Beer, T., 2016. Development and validation of an at-line fast and non-destructive Raman spectroscopic method for the quantification of multiple components in liquid detergent compositions. Analytica chimica acta 941, 26-34.

Dadou, S.M., El-Barghouthi, M.I., Antonijevic, M.D., Chowdhry, B.Z., Badwan, A.A., 2020. Elucidation of the Controlled-Release Behavior of Metoprolol Succinate from Directly Compressed Xanthan Gum/Chitosan Polymers: Computational and Experimental Studies. ACS Biomaterials Science \& Engineering 6, 21-37.

De Leersnyder, F., Peeters, E., Djalabi, H., Vanhoorne, V., Van Snick, B., Hong, K., Hammond, S., Liu, A.Y., Ziemons, E., Vervaet, C., 2018. Development and validation of an in-line NIR spectroscopic method for continuous blend potency determination in the feed frame of a tablet press. Journal of pharmaceutical and biomedical analysis 151, 274-283.

EMA, 2009. Guideline on the use of near infrared spectroscopy by the pharmaceutical industry and the data requirements for new submissions and variations. European Medicines Agency.

FDA, 2004. Guidance for industry, PAT-A Framework for Innovative Pharmaceutical Development, Manufacturing and Quality Assurance, http://www.fda.gov/cder/guidance/published.html.

FDA, 2015. Development and Submission of Near Infrared Analytical Procedures-Guidance for Industry. US Department of Health and Human Services.

FDA, 2019. Quality considerations for continuous manufacturing-Guidance for industrydraft guidance.

Fonteyne, M., Vercruysse, J., De Leersnyder, F., Van Snick, B., Vervaet, C., Remon, J.P., De Beer, T., 2015. Process Analytical Technology for continuous manufacturing of solid-dosage forms. TrAC Trends in Analytical Chemistry 67, 159-166.

Gabrielsson, J., Lindberg, N.O., Lundstedt, T., 2002. Multivariate methods in pharmaceutical applications. Journal of Chemometrics: A Journal of the Chemometrics Society 16, 141-160. 
Gouveia, F.F., Rahbek, J.P., Mortensen, A.R., Pedersen, M.T., Felizardo, P.M., Bro, R., Mealy, M.J., 2017. Using PAT to accelerate the transition to continuous API manufacturing. Analytical and bioanalytical chemistry 409, 821-832.

Hubert, P., Nguyen-Huu, J.-J., Boulanger, B., Chapuzet, E., Cohen, N., Compagnon, P.-A., Dewé, W., Feinberg, M., Laurentie, M., Mercier, N., 2007. Harmonization of strategies for the validation of quantitative analytical procedures: a SFSTP proposal-part III. Journal of pharmaceutical and biomedical analysis 45, 82-96.

ICH, 2005. Validation of analytical procedures: text and methodology Q2 (R1), International conference on harmonization, Geneva, Switzerland, pp. 11-12.

ICH, 2009. ICH Harmonised Tripartite Guideline: Pharmaceutical Development Q8 (R2).

Kelleher, J., Gilvary, G., Madi, A., Jones, D., Li, S., Tian, Y., Almajaan, A., Senta-Loys, Z., Andrews, G., Healy, A., 2018. A comparative study between hot-melt extrusion and spraydrying for the manufacture of anti-hypertension compatible monolithic fixed-dose combination products. International journal of pharmaceutics 545, 183-196.

Kelly, A.L., Gough, T., Dhumal, R.S., Halsey, S., Paradkar, A., 2012. Monitoring ibuprofennicotinamide cocrystal formation during solvent free continuous cocrystallization (SFCC) using near infrared spectroscopy as a PAT tool. International journal of pharmaceutics 426, $15-20$.

Kleinebudde, P., Khinast, J., Rantanen, J., 2017. Continuous manufacturing of pharmaceuticals. John Wiley \& Sons.

Lang, B., McGinity, J.W., Williams III, R.O., 2014. Hot-melt extrusion-basic principles and pharmaceutical applications. Drug development and industrial pharmacy 40, 1133-1155.

Laske, S., Paudel, A., Scheibelhofer, O., Sacher, S., Hoermann, T., Khinast, J., Kelly, A., Rantannen, J., Korhonen, O., Stauffer, F., 2017. A review of PAT strategies in secondary solid oral dosage manufacturing of small molecules. Journal of Pharmaceutical Sciences 106, 667712 .

Lee, S.L., 2017. Modernizing the way drugs are made: a transition to continuous manufacturing, from $\quad$ Retrieved FDA: https://www.fda.gov/Drugs/NewsEvents/ucm557448.htm.

Lee, S.L., O'Connor, T.F., Yang, X., Cruz, C.N., Chatterjee, S., Madurawe, R.D., Moore, C.M., Lawrence, X.Y., Woodcock, J., 2015. Modernizing pharmaceutical manufacturing: from batch to continuous production. Journal of Pharmaceutical Innovation 10, 191-199.

Li, Y., Anderson, C.A., Drennen III, J.K., Airiau, C., Igne, B., 2018. Method development and validation of an inline process analytical technology method for blend monitoring in the tablet feed frame using Raman spectroscopy. Analytical chemistry 90, 8436-8444.

Moore, C., 2012. Quality by Design -FDA Lessons Learned and Challenges for International Harmonization, Presentation at International Conference on Drug Development.

Müller, J., Brock, D., Knop, K., Zeitler, J.A., Kleinebudde, P., 2012. Prediction of dissolution time and coating thickness of sustained release formulations using Raman spectroscopy and terahertz pulsed imaging. European Journal of Pharmaceutics and Biopharmaceutics 80, 690697.

Nagy, B., Farkas, A., Gyürkés, M., Komaromy-Hiller, S., Démuth, B., Szabó, B., Nusser, D., Borbás, E., Marosi, G., Nagy, Z.K., 2017. In-line Raman spectroscopic monitoring and feedback 
control of a continuous twin-screw pharmaceutical powder blending and tableting process. International journal of pharmaceutics 530, 21-29.

Netchacovitch, L., Thiry, J., De Bleye, C., Chavez, P.-F., Krier, F., Sacré, P.-Y., Evrard, B., Hubert, P., Ziemons, E., 2015. Vibrational spectroscopy and microspectroscopy analyzing qualitatively and quantitatively pharmaceutical hot melt extrudates. Journal of pharmaceutical and biomedical analysis 113, 21-33.

Ohno, T., 1988. Toyota production system: beyond large-scale production. crc Press.

Pauli, V., Roggo, Y., Pellegatti, L., Trung, N.Q.N., Elbaz, F., Ensslin, S., Kleinebudde, P., Krumme, M., 2019. Process analytical technology for continuous manufacturing tableting processing: A case study. Journal of pharmaceutical and biomedical analysis 162, 101-111.

Poechlauer, P., Manley, J., Broxterman, R., Gregertsen, B.r., Ridemark, M., 2012. Continuous processing in the manufacture of active pharmaceutical ingredients and finished dosage forms: an industry perspective. Organic Process Research \& Development 16, 1586-1590.

Reitz, E., Podhaisky, H., Ely, D., Thommes, M., 2013. Residence time modeling of hot melt extrusion processes. European Journal of Pharmaceutics and Biopharmaceutics 85, 1200-1205.

Repka, M.A., Koleng, J.J., Zhang, F., McGinity, J.W., 2013. Hot-melt extrusion technology, Encyclopedia of Pharmaceutical Science and Technology, Six Volume Set (Print). CRC Press, pp. 1855-1876.

Saerens, L., Ghanam, D., Raemdonck, C., Francois, K., Manz, J., Krüger, R., Krüger, S., Vervaet, C., Remon, J.P., De Beer, T., 2014a. In-line solid state prediction during pharmaceutical hotmelt extrusion in a $12 \mathrm{~mm}$ twin screw extruder using Raman spectroscopy. European Journal of Pharmaceutics and Biopharmaceutics 87, 606-615.

Saerens, L., Segher, N., Vervaet, C., Remon, J.P., De Beer, T., 2014b. Validation of an in-line Raman spectroscopic method for continuous active pharmaceutical ingredient quantification during pharmaceutical hot-melt extrusion. Analytica chimica acta 806, 180-187.

Sahnić, D., Mestrović, E., Jednačak, T., Habinovec, I., Parlov Vuković, J., Novak, P., 2016. Monitoring and quantification of omeprazole synthesis reaction by in-line Raman spectroscopy and characterization of the reaction components. Organic Process Research \& Development 20, 2092-2099.

Shafiq, S., Shakeel, F., 2008. Enhanced stability of ramipril in nanoemulsion containing Cremophor-EL: A technical note. Aaps Pharmscitech 9, 1097-1101.

WHO, 2015. General guidance on hold-time studies. Technical Report Series.

Wirges, M., Funke, A., Serno, P., Knop, K., Kleinebudde, P., 2013. Development and in-line validation of a Process Analytical Technology to facilitate the scale up of coating processes. Journal of pharmaceutical and biomedical analysis 78, 57-64.

Woodcock, J., Woosley, R., 2008. The FDA critical path initiative and its influence on new drug development. Annu. Rev. Med. 59, 1-12.

Zhang, S., Xiong, H., Zhou, L., Ju, W., Yang, Z., Yan, K., Yan, B., Qu, H., 2019. Development and validation of in-line near-infrared spectroscopy based analytical method for commercial production of a botanical drug product. Journal of pharmaceutical and biomedical analysis $174,674-682$. 
Table 1. Overview of variables and responses that were used to build the HME process design space

\begin{tabular}{lcccc}
\hline & \multicolumn{2}{c}{ Variables } & & \\
\cline { 2 - 3 } Name & Abbreviation & Unit & Lower limit & Upper limit \\
\hline TEC concentration & TEC & $\%$ & 0 & 10 \\
Feed rate & FR & rpm & 10 & 40 \\
Screw Speed & $\mathrm{SS}$ & $\mathrm{rpm}$ & 50 & 100 \\
Temperature & $\mathrm{T}$ & ${ }^{\circ} \mathrm{C}$ & 100 & 140 \\
\hline \multirow{4}{*}{ Name } & \multicolumn{2}{c}{ Responses } & & \\
\cline { 2 - 3 } Ramipril & Abbreviation & Unit & Lower limit & Upper limit \\
\hline Ramipril-Diketopiperazine & RMP & $\%$ & 9 & 11 \\
\hline
\end{tabular}


Table 2. Overview of the combinations of the formulation and process variables adopted for the HME processing and the results obtained for the responses.

\begin{tabular}{|c|c|c|c|c|c|c|}
\hline & \multicolumn{4}{|c|}{ Variable } & \multicolumn{2}{|c|}{ Response } \\
\hline & $\begin{array}{l}\text { TEC } \\
(\%)\end{array}$ & $\begin{array}{c}\mathrm{FR} \\
(\mathrm{rpm})\end{array}$ & $\begin{array}{c}\text { SS } \\
\text { (rpm) }\end{array}$ & $\begin{array}{c}\mathrm{T} \\
\left({ }^{\circ} \mathrm{C}\right)\end{array}$ & $\operatorname{RMP}(\%)^{*}$ & $\begin{array}{c}\text { RMP-DKP } \\
(\%)^{*}\end{array}$ \\
\hline N1 & 0 & 10 & 50 & 100 & $9.2 \pm 0.2$ & $1.2 \pm 0.6$ \\
\hline N2 & 10 & 10 & 50 & 100 & $8.6 \pm 0.2$ & $2.8 \pm 0.2$ \\
\hline N3 & 0 & 40 & 50 & 100 & - & - \\
\hline N4 & 10 & 40 & 50 & 100 & $10.0 \pm 0.1$ & $0.5 \pm 0.1$ \\
\hline N5 & 0 & 10 & 100 & 100 & $8.4 \pm 0.3$ & $1.6 \pm 0.1$ \\
\hline N6 & 10 & 10 & 100 & 100 & $8.7 \pm 0.1$ & $2.1 \pm 0.1$ \\
\hline N7 & 0 & 40 & 100 & 100 & - & - \\
\hline N8 & 10 & 40 & 100 & 100 & $10.2 \pm 0.4$ & $2.3 \pm 0.2$ \\
\hline N9 & 0 & 10 & 50 & 140 & $2.0 \pm 0.2$ & $7.9 \pm 0.5$ \\
\hline N10 & 10 & 10 & 50 & 140 & $1.6 \pm 0.1$ & $8.6 \pm 1.3$ \\
\hline N11 & 0 & 40 & 50 & 140 & $7.7 \pm 0.4$ & $2.7 \pm 0.6$ \\
\hline N12 & 10 & 40 & 50 & 140 & $6.5 \pm 0.5$ & $4.1 \pm 0.5$ \\
\hline N13 & 0 & 10 & 100 & 140 & $2.7 \pm 0.5$ & $8.7 \pm 0.7$ \\
\hline N14 & 10 & 10 & 100 & 140 & $1.8 \pm 0.2$ & $7.9 \pm 0.8$ \\
\hline N15 & 0 & 40 & 100 & 140 & $6.3 \pm 0.2$ & $3.6 \pm 0.3$ \\
\hline N16 & 10 & 40 & 100 & 140 & $6.6 \pm 0.2$ & $4.6 \pm 0.3$ \\
\hline N17 & 5 & 25 & 75 & 120 & $9.1 \pm 0.7$ & $1.8 \pm 0.2$ \\
\hline N18 & 5 & 25 & 75 & 120 & $9.0 \pm 0.1$ & $1.6 \pm 0.0$ \\
\hline N19 & 5 & 25 & 75 & 120 & $8.7 \pm 0.1$ & $1.4 \pm 0.0$ \\
\hline N20 & 0 & 25 & 75 & 120 & $8.8 \pm 0.1$ & $1.2 \pm 0.1$ \\
\hline
\end{tabular}

*Values were obtained offline using HPLC and represent the average \pm standard deviation ( $n=3$ ) 
Table 3. Process predictions for the validation of the DoE model; HPLC was used as the reference method of quantification ${ }^{a}$

\begin{tabular}{|c|c|c|c|c|c|c|c|c|c|c|c|c|}
\hline & \multirow{3}{*}{$\begin{array}{c}\text { TEC } \\
(\% \mathrm{w} / \mathrm{w})\end{array}$} & \multicolumn{3}{|c|}{ Variable } & \multicolumn{8}{|c|}{ Response } \\
\hline & & \multirow{2}{*}{$\underset{(\mathrm{rpm})}{\mathrm{FR}}$} & \multirow{2}{*}{$\underset{(\mathrm{rpm})}{\mathrm{SS}}$} & \multirow{2}{*}{$\begin{array}{c}\mathrm{T} \\
\left({ }^{\circ} \mathrm{C}\right)\end{array}$} & \multirow[b]{2}{*}{$\mathbf{P}$} & \multicolumn{2}{|c|}{$\operatorname{RMP}(\% \mathrm{w} / \mathrm{w})$} & \multirow[b]{2}{*}{$\mathbf{M}^{\mathrm{b}}$} & \multicolumn{4}{|c|}{ RMP-DKP (\% w/w) } \\
\hline & & & & & & $\bar{L}$ & $\bar{U}$ & & $\mathbf{P}$ & $\mathbf{L}$ & $\mathbf{U}$ & $\mathbf{M}^{\mathrm{b}}$ \\
\hline V1 & 10 & 25 & 75 & 120 & 8.7 & 8.3 & 9.1 & $8.3(0.5)$ & 1.9 & 1.6 & 2.4 & $0.9(0.3)$ \\
\hline V2 & 5 & 15 & 75 & 140 & 4.0 & 3.5 & 4.5 & $4.3(0.6)$ & 5.1 & 3.9 & 6.6 & $4.9(0.5)$ \\
\hline V3 & 10 & 20 & 50 & 100 & 10.4 & 10.0 & 10.8 & $10.0(0.3)$ & 0.9 & 0.7 & 1.2 & $0.7(0.1)$ \\
\hline V4 & 6 & 30 & 100 & 110 & 10.0 & 9.6 & 10.4 & $9.7(0.5)$ & 1.0 & 0.7 & 1.3 & $0.8(0.1)$ \\
\hline V5 & 10 & 25 & 100 & 140 & 6.3 & 5.8 & 6.8 & $6.1(0.8)$ & 5.1 & 3.9 & 6.6 & $3.2(0.6)$ \\
\hline V6 & 8 & 34 & 80 & 103 & 10.6 & 10.2 & 10.9 & $9.9(0.5)$ & 0.9 & 0.6 & 1.1 & $0.6(0.2)$ \\
\hline
\end{tabular}

${ }^{a} P$, values predicted from the DoE model; $L$, lower limit; $U$, upper limit; $M$, values measured using HPLC. ${ }^{b}$ Numbers between parentheses represent standard deviation ( $\left.n=3\right)$. 
Table 4. Calibration parameters calculated from the PLS models developed using Raman spectra that were collected and preprocessed using different spectral filters*

\begin{tabular}{lccccc}
\hline Spectral filter & $\mathbf{R}^{2} \mathbf{X}$ & $\mathbf{R}^{\mathbf{2}} \mathbf{Y}$ & $\mathbf{Q}^{\mathbf{2}}$ & $\mathbf{R M S E E}$ & $\mathbf{R M S E c v}$ \\
\hline Raw spectra & 1 & 0.909 & 0.909 & 0.886 & 0.885 \\
SNV & 0.976 & 0.961 & 0.954 & 0.587 & 0.627 \\
MSC & 0.973 & 0.955 & 0.950 & 0.624 & 0.660 \\
$\mathbf{1}^{\text {st }} \mathbf{D}$ & 0.916 & 0.922 & 0.986 & 0.823 & 0.953 \\
$\mathbf{2}^{\text {nd }} \mathbf{D}$ & 0.792 & 0.803 & 0.734 & 1.288 & 1.500 \\
MSC:SNV:SG & 0.983 & 0.955 & 0.950 & 0.628 & 0.660 \\
1 $^{\text {st }} \mathbf{D}:$ MSC:SNV:SG & 0.754 & 0.89 & 0.859 & 0.987 & 1.162 \\
2 $^{\text {nd }} \mathbf{D}:$ MSC:SNV:SG & 0.55 & 0.844 & 0.772 & 1.179 & 1.417 \\
\hline
\end{tabular}

${ }^{*} R^{2} X, R^{2}$ predicted; $R^{2} Y, R^{2}$ observed; $Q^{2}$, model validity; $R M S E E$, root mean square error of estimation; $R M S E c v$, root mean square error of cross validation; SNV, standard normalised variate; MSC, multiplicative scatter correction; $S G$, Savitzky-Golay; $1^{\text {st }} D$, first derivative; $2^{\text {nd }} D$, second derivative. 
Table 5. Linearity and accuracy validation parameter obtained for each Raman based PLS calibration model.

\begin{tabular}{lccc}
\hline Parameter & Model 1 & Model 2 & Model 3 \\
\hline Linearity & & & \\
$\mathrm{R}^{2}$ & 0.989 & 0.995 & 0.992 \\
Slope & 1 & 1 & 1 \\
Intercept & $-1.24 \mathrm{e}-07$ & $2.01 \mathrm{e}-07$ & $1.31 \mathrm{e}-07$ \\
\hline Accuracy & & & \\
RMSEE (\%) & 0.308 & 0.235 & 0.304 \\
RMSEcv (\%) & 0.306 & 0.258 & 0.304 \\
RMSEP (\%) & 0.487 & 0.635 & 0.625 \\
\hline
\end{tabular}


Table 6. Precision parameters calculated for the validation set using the three established PLS calibration models*

\begin{tabular}{|c|c|c|c|c|c|c|c|c|c|c|c|c|}
\hline \multirow{3}{*}{$\begin{array}{c}\text { RMP } \\
(\%)\end{array}$} & \multicolumn{4}{|c|}{$\underline{\text { Model } 1}$} & \multicolumn{4}{|c|}{$\underline{\text { Model } 2}$} & \multicolumn{4}{|c|}{$\underline{\text { Model } 3}$} \\
\hline & \multicolumn{2}{|c|}{$\underline{\text { Intraday }}$} & \multicolumn{2}{|c|}{ Interday } & \multicolumn{2}{|c|}{$\underline{\text { Intraday }}$} & \multicolumn{2}{|c|}{ Interday } & \multicolumn{2}{|c|}{$\underline{\text { Intraday }}$} & \multicolumn{2}{|c|}{ Interday } \\
\hline & RSD & RMSEP & RSD & RMSEP & RSD & RMSEP & RSD & RMSEP & RSD & RMSEP & RSD & RMSEP \\
\hline 4 & 2.76 & 0.15 & 3.91 & 0.34 & 2.20 & 0.45 & 5.54 & 0.42 & 6.90 & 0.67 & 5.87 & 0.61 \\
\hline 6 & 1.24 & 0.55 & 3.95 & 0.66 & 2.09 & 0.56 & 4.07 & 0.49 & 1.81 & 0.11 & 3.49 & 0.47 \\
\hline 7 & 4.12 & 0.83 & 3.85 & 0.85 & 3.37 & 0.80 & 2.64 & 0.74 & 2.69 & 0.26 & 3.71 & 0.41 \\
\hline 9 & 4.91 & 0.41 & 3.24 & 0.56 & 2.18 & 0.20 & 2.06 & 0.36 & 2.20 & 0.21 & 2.33 & 0.42 \\
\hline
\end{tabular}

${ }^{*} R S D$, relative standard deviation; RMSEP, root mean square error of prediction. Values reported are in (\%). 

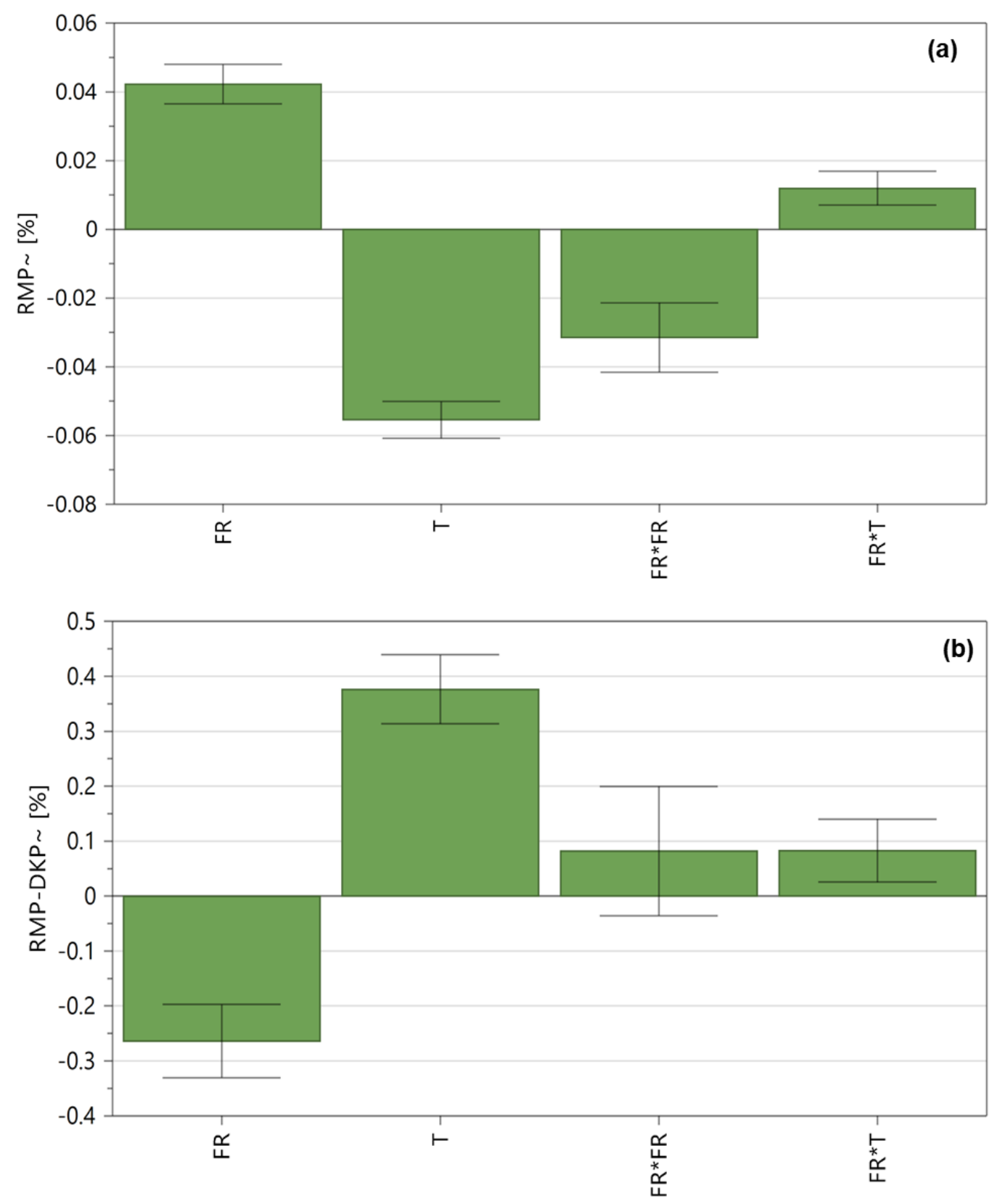

Figure 1. Coefficients plots representing variables affecting (a) the stability of RMP and (b) the formation of RMP-DKP during HME process as determined by the DoE study. 
Design Space

Probability of failure (\%) for RMP

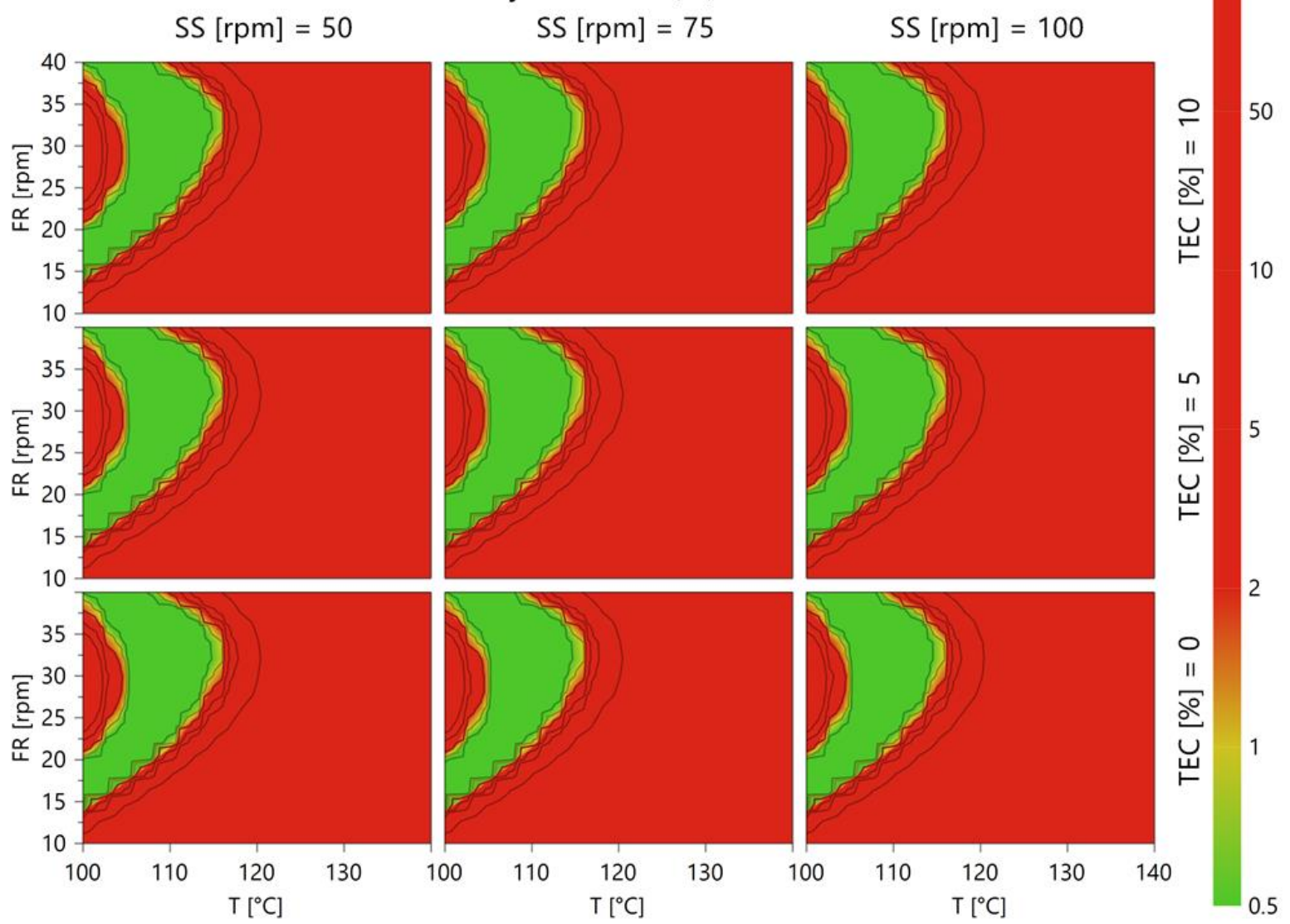

Figure 2. Design space obtained from the DoE model. Colour scale bar on the right-hand side represents the probability of failure for variables to generate the response, RMP (\%), within the targeted range. RMP was quantified offline using HPLC. 

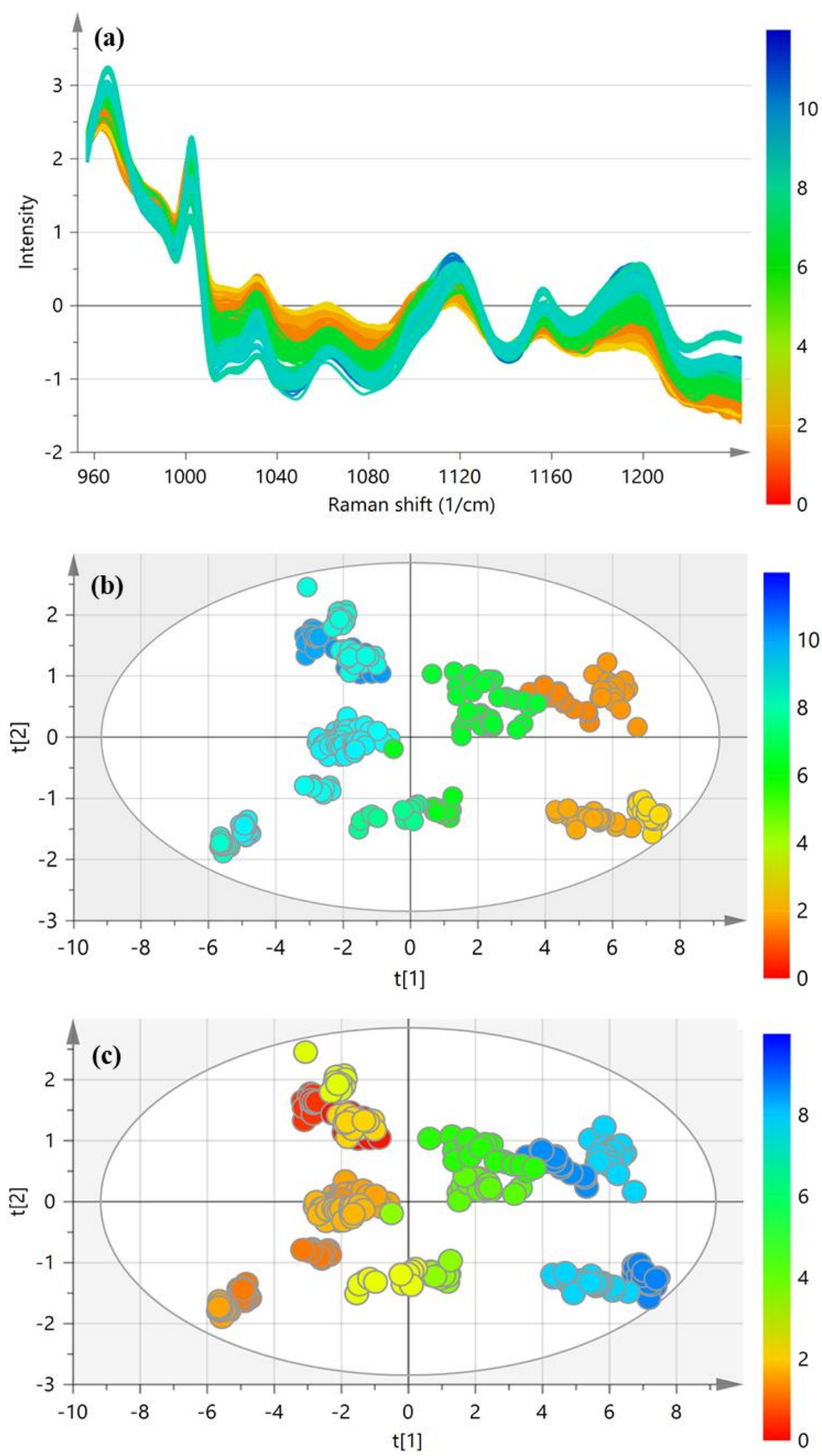

Figure 3. (a) Raman spectra obtained from the wavenumber region $950-1250 \mathrm{~cm}^{-1}$ during HME. PC 1 versus PC 2 scores scatterplots generated for (b) RMP and (c) RMP-DKP from the collected inline Raman spectra. Colour code, which represents the concentration $(\%$ w/w) of RMP (a, b) and RMP-DKP (c) measured using offline HPLC, is on the right side of the plots. 

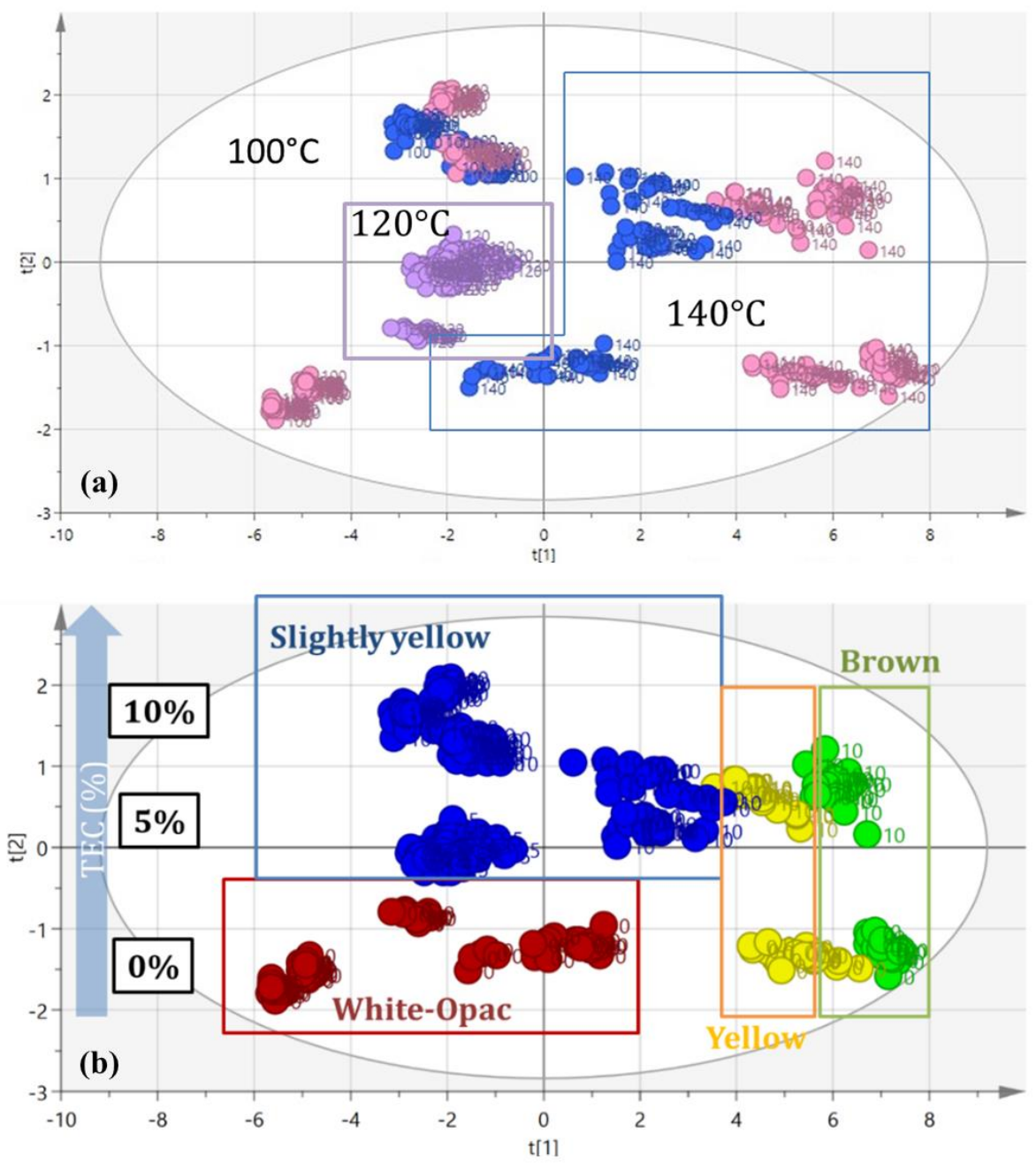

Figure 4. PCA scatterplots showing: (a) the effects of FR (at $10 \mathrm{rpm}$, pink; $25 \mathrm{rpm}$, purple; and $40 \mathrm{rpm}$, blue) and T.(b) TEC concentration (0,5 and 10\%) along PC 2; while the appearance of the produced extrudates are presented in a colour code as follows:

White-Opaque, Red; light yellow, blue; yellow, yellow; and brown, green. 


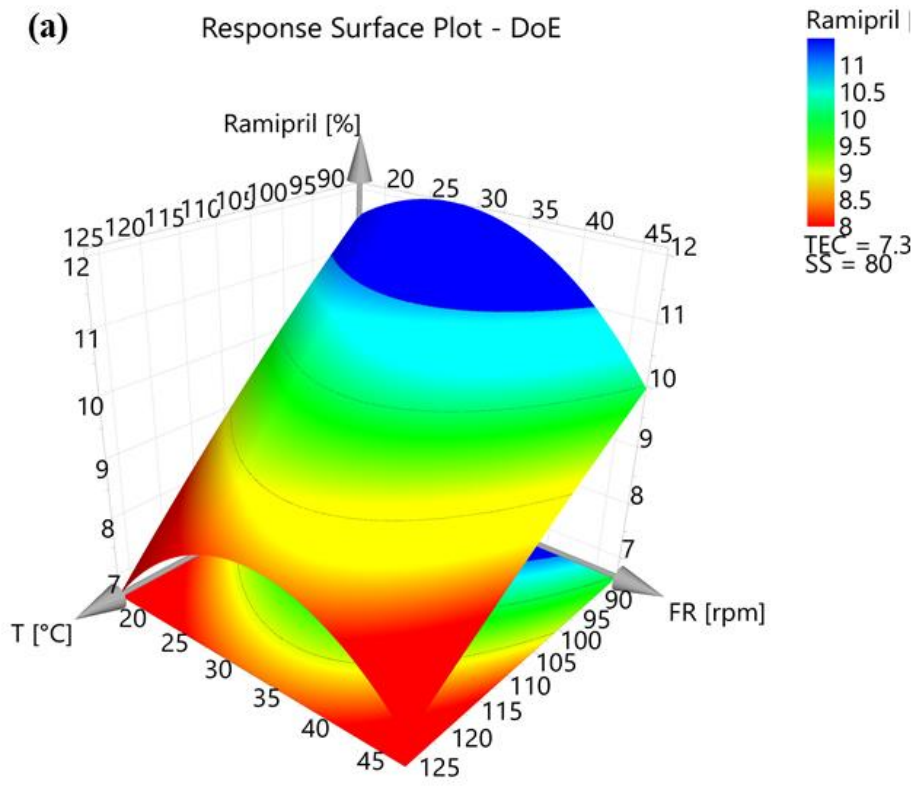

(b) Dynamic Profile - Optimizer Setpoint

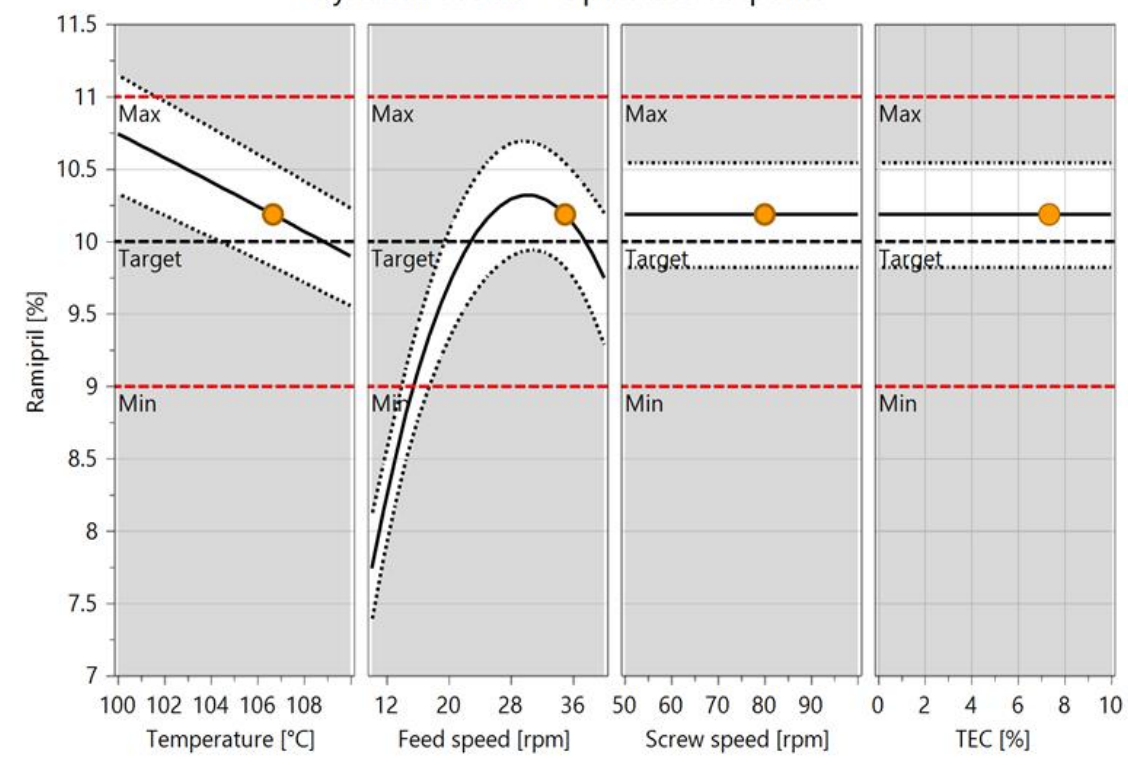

Figure 5. (a) Response surface and (b) dynamic plots showing the predicted RMP concentration at different combinations/limits of the studied variables, and the set point that result in the optimum content of RMP in the extrudates $(T=106, F R=32, S S=80, T E C=$ 7.3). Colour code on the right side of the figure (a) represents the concentration of RMP in the extrudates (\% w/w) measured using HPLC. 

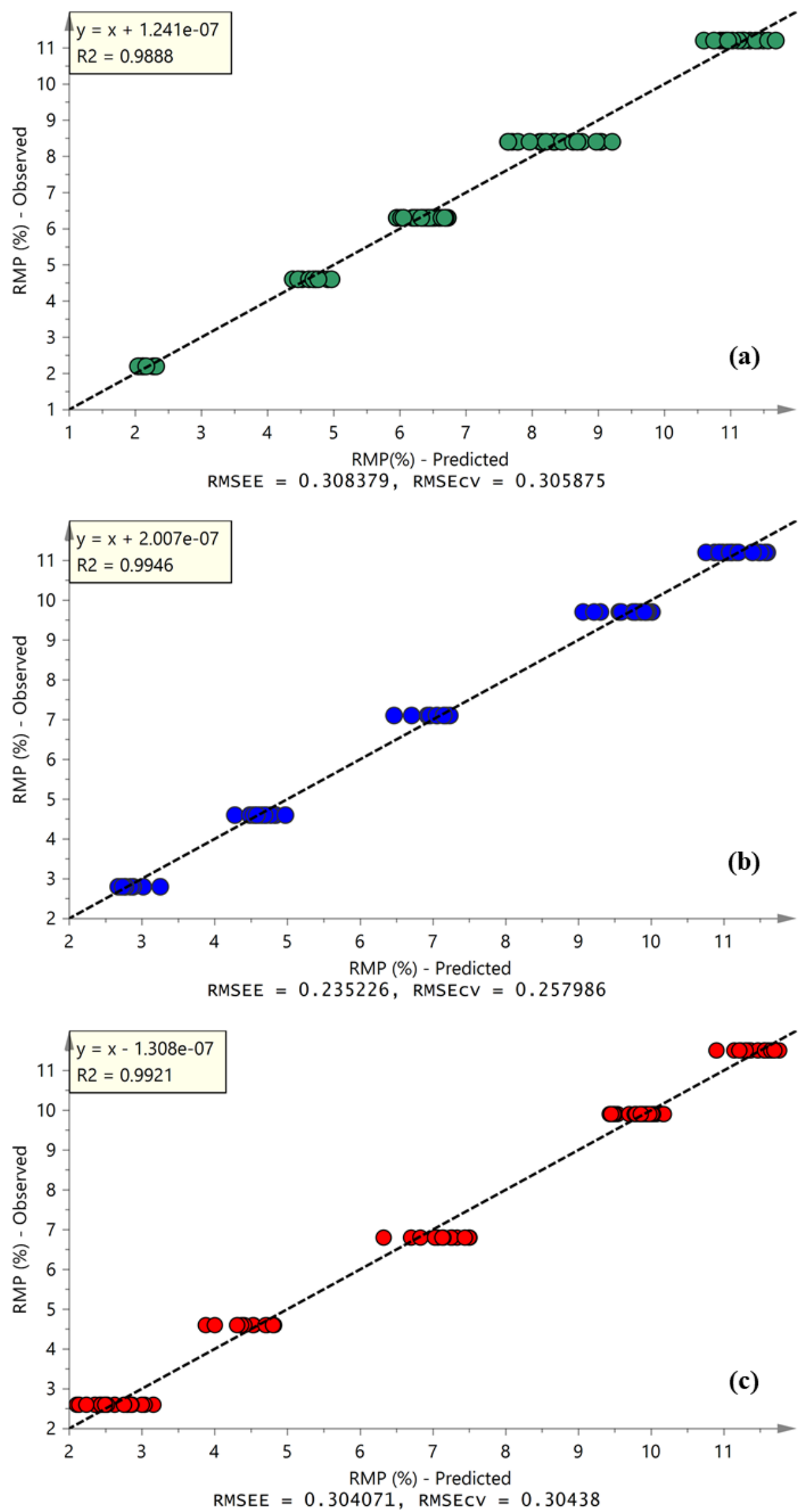

Figure 6. The developed PLS calibration models. (a) Model 1, (b) Model 2 and (c) Model 3. 
DModX Plot - Model 1

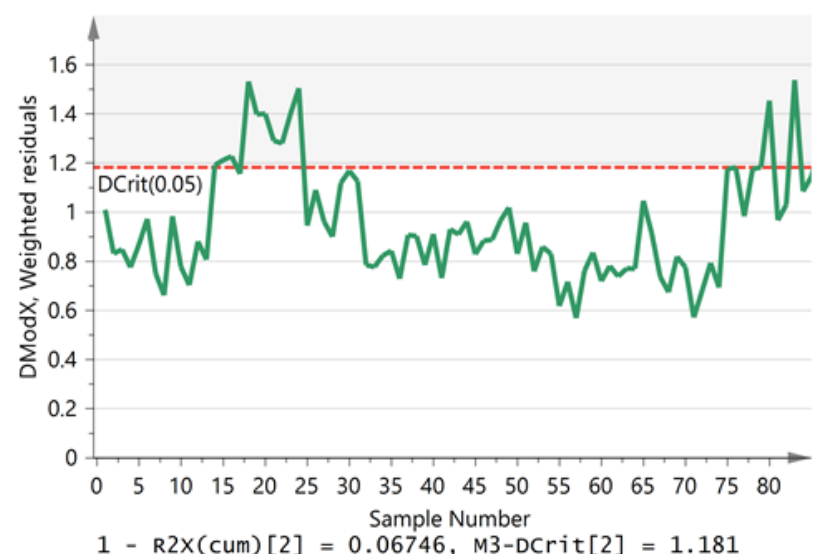

DModX Plot - Model 2

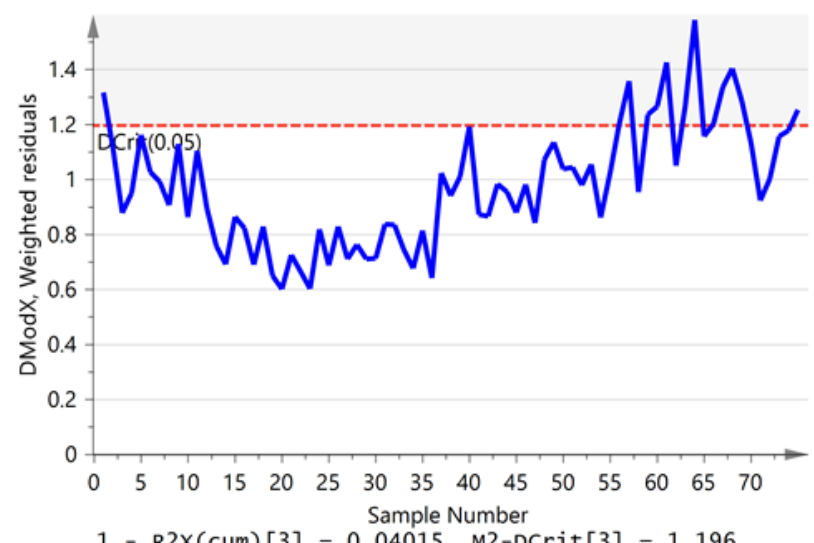

DModX Plot - Model 3

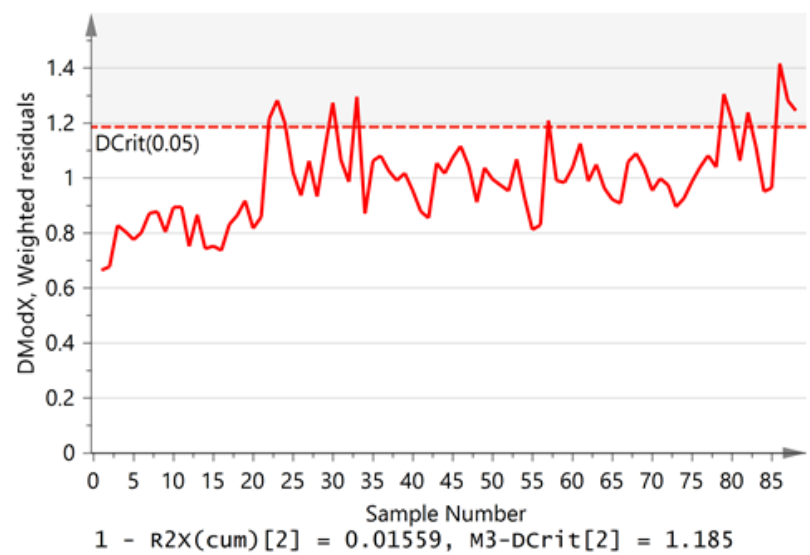

Hotelling's T2 Plot - Model 1

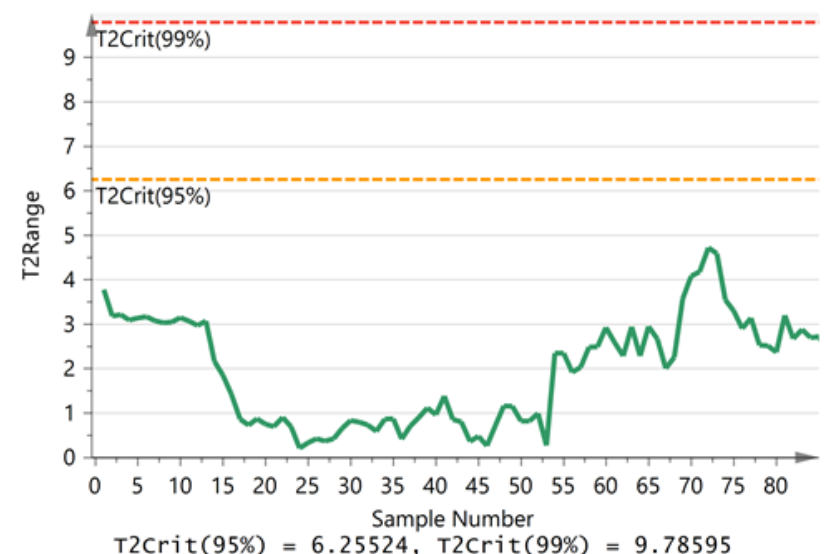

Hotelling's T2 Plot - Model 2

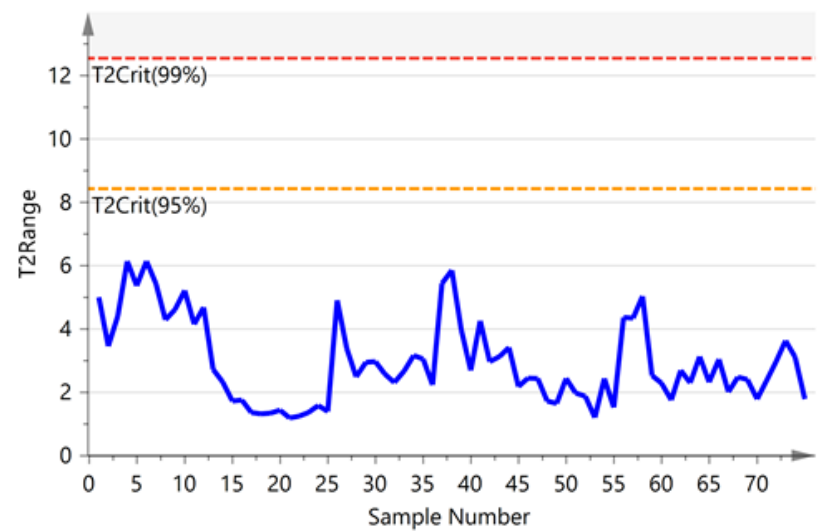

$\operatorname{T2Crit}(95 \%)=8.42305, \operatorname{T2Crit}(99 \%)=12.5364$

Hotelling's T2 Plot - Model 3

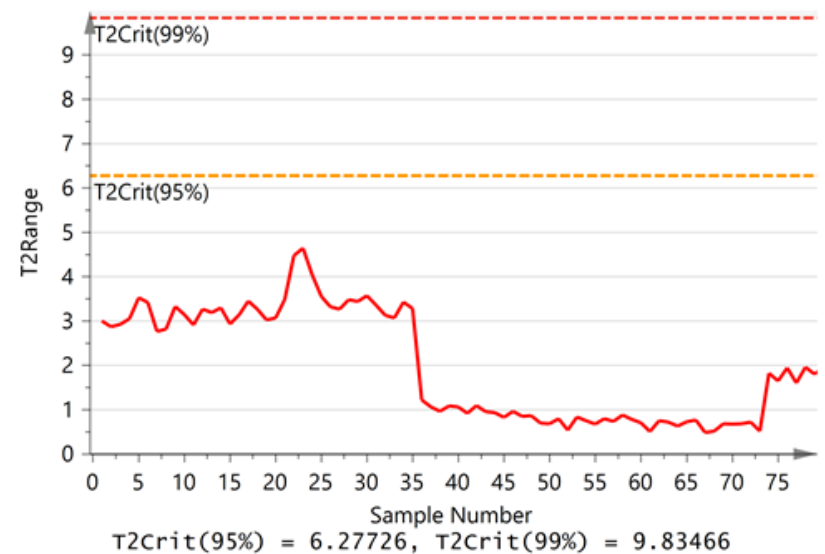

Figure 7. Distance (DModX) and Hoteling's T2 Plots obtained from the three developed PLS calibration models. Model 1, green; Model 2, blue and Model 3, red. 

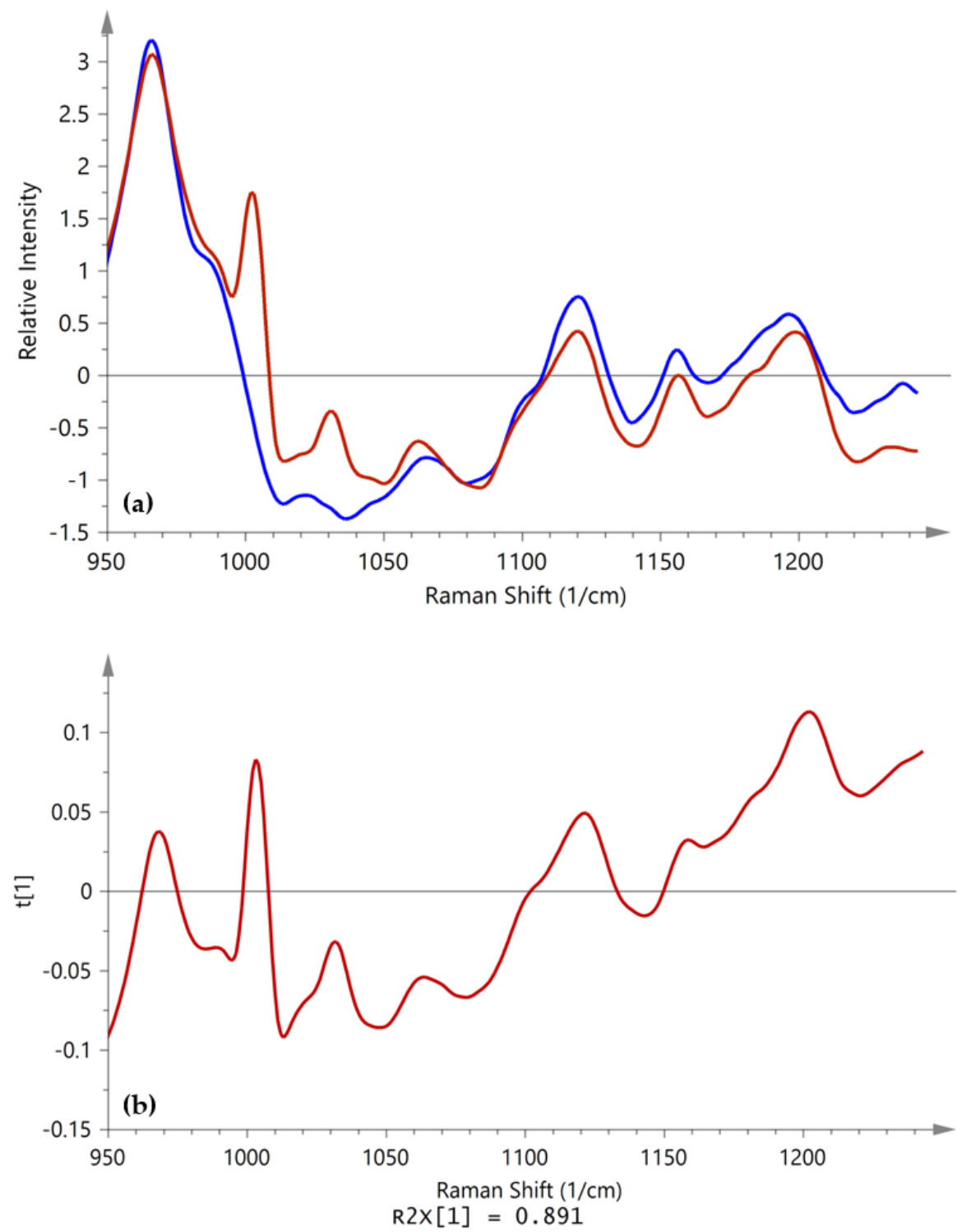

Figure 8. (a) Raman spectra obtained from the extrudates with (red) and without (blue) Ramipril. (b) Loading plot of the first principal component obtained from the Raman based PLS calibration (model 3). 


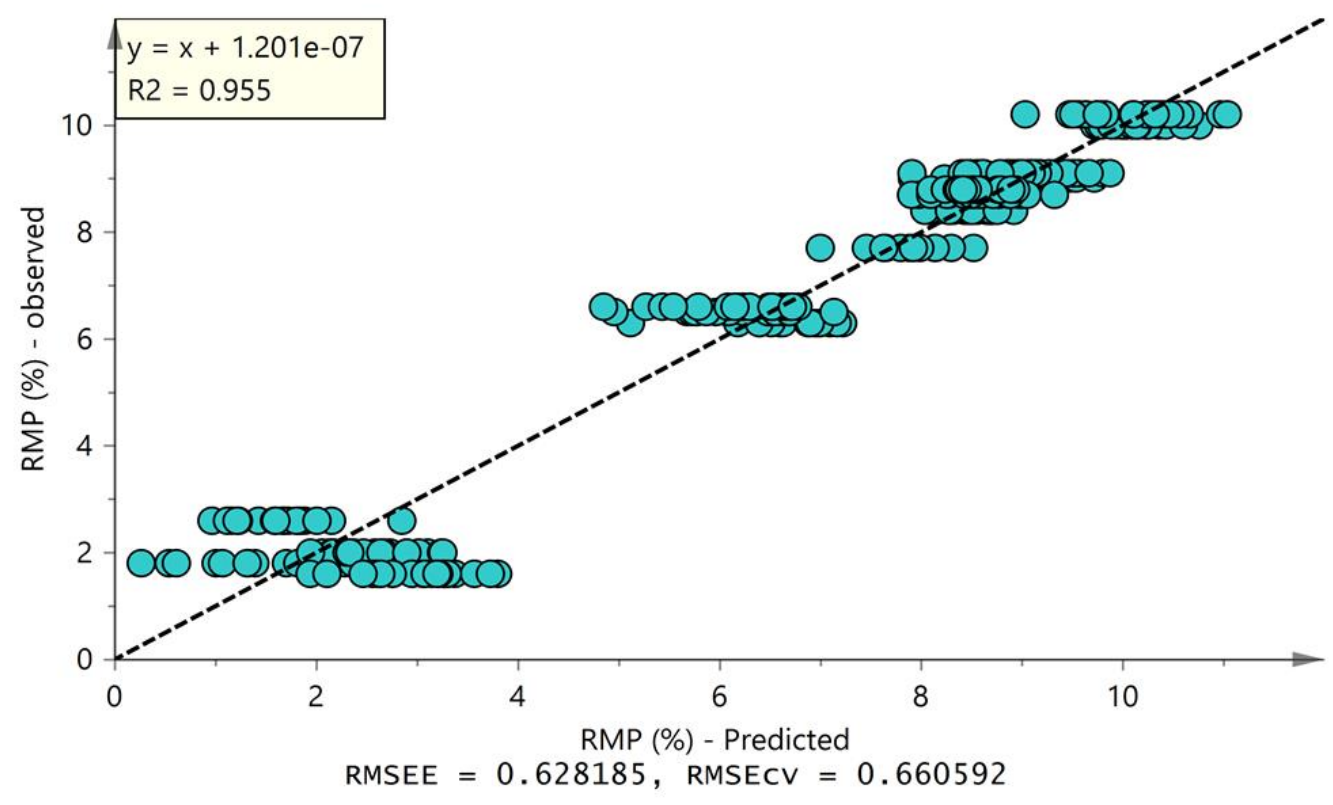

Figure 9. PLS calibration model developed using the collected inline Raman spectra during the 20 DoE extrusion runs vs the concentration of RMP in the extrudates measured using offline HPLC. 


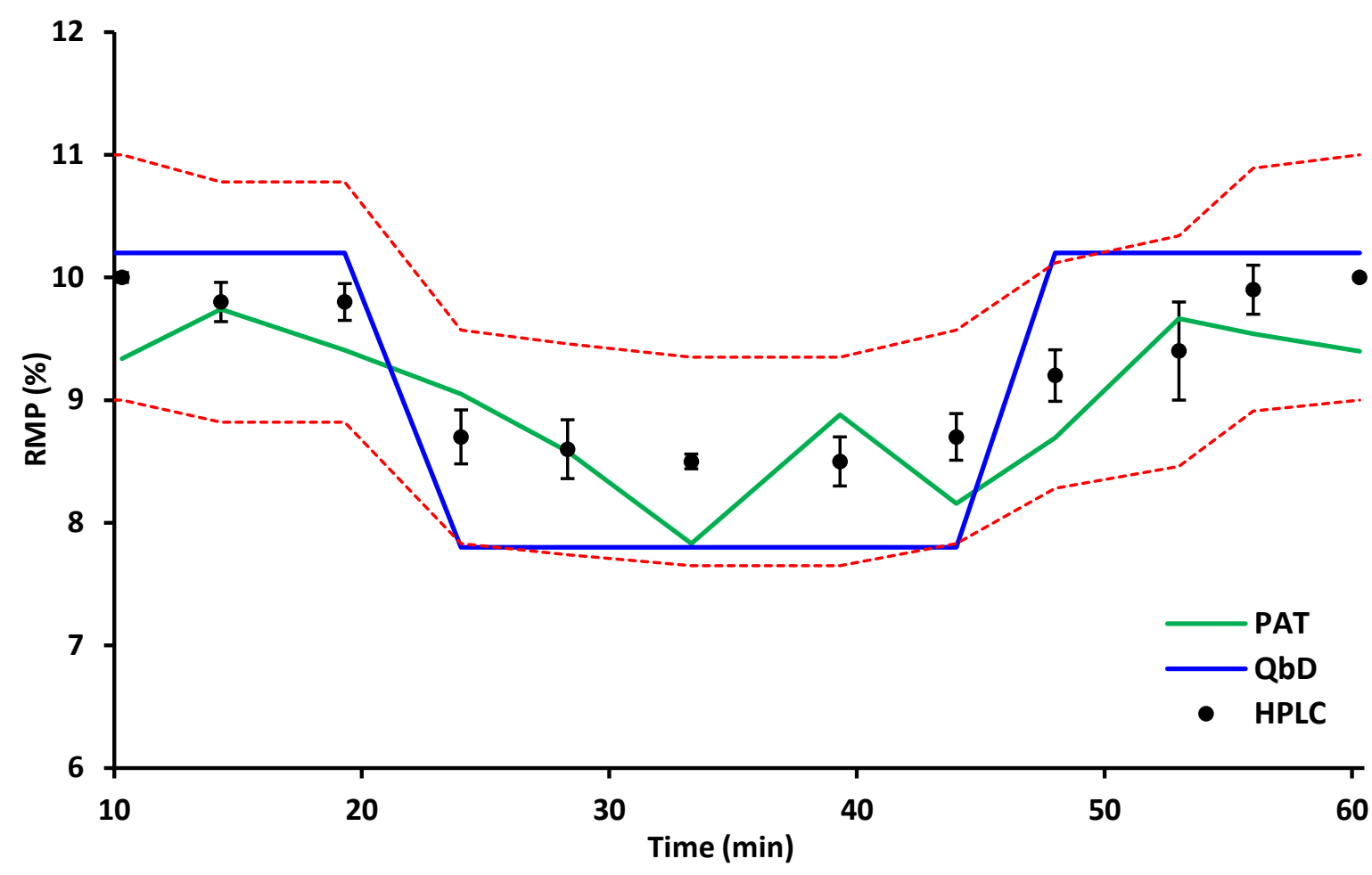

Figure 10. Ramipril content profile monitored for $60 \mathrm{~min}$ during the HME process at varied FR $(0-19 \mathrm{~min}=35 \mathrm{rpm}, 20-44 \mathrm{~min}=10 \mathrm{rpm}$ and $45-60 \mathrm{~min}=35 \mathrm{rpm})$. The process was allowed to stabilise for $10 \mathrm{~min}$ at FR $35 \mathrm{rpm}$ before collecting the inline Raman spectra. Values of RMP (\%) were recorded as predicted from the design space (QbD) and the PLS based PAT method (PAT), and as the true values (HPLC). Dashed lines represent the relative error from the true HPLC values $( \pm 10 \%)$. 